\title{
The Labor Market Effects of Employer Recruitment Choice
}

\author{
Jed DeVaro* \\ Department of Labor Economics \\ 357 Ives Hall East \\ Cornell University \\ Ithaca, NY 14853, U.S.A. \\ Email: devaro@cornell.edu
}

July 18,2007

\begin{abstract}
I analyze employer recruitment decisions using a dynamic, discrete-choice structural model that I estimate on a sample of clerical workers from the MCSUI, a large cross section of establishments in 4 metropolitan areas of the U.S. In the model, employers choose either informal recruitment methods (which generate a small but select applicant pool from which the employer can hire quickly) or formal methods (which create a large but less select applicant pool which the employer must screen intensively, delaying hiring times). I study the effects of 3 counterfactual simulations on recruitment strategies, starting wages, and vacancy durations: a wage subsidy, a policy designed to improve information about prospective matches, and an increase in the heterogeneity of prospective matches. I show that the effects of exogenous policy or environmental changes can be decomposed into "pure wage effects" that affect the wage offers employers post, holding constant their recruitment strategies, and "recruitment-wage effects" that involve changes in recruitment methods. The results show that changes in recruitment strategies represent an important channel through which changes in the economic environment affect the starting wages and vacancy duration for new hires.
\end{abstract}

JEL Classification: M51

Keywords: Recruitment, Screening, Work Opportunity Tax Credit, Welfare-to-Work Tax Credit, Workforce Investment Act of 1998, Dynamic Structural Model

\footnotetext{
* I am grateful to Tom MaCurdy, John Pencavel, Ed Lazear, Luigi Pistaferri, Jay Bhattacharya, Jun Ishii, Henri Fraisse, Joshua Pinkston, three anonymous referees, the editor, and numerous colleagues for helpful comments on this work, and to the Kapnick Foundation for financial support.
} 


\section{INTRODUCTION}

Employers and job seekers are brought together for potential matches through recruitment and job search activities that help both parties acquire information about the other. The better the information they obtain prior to entering an employment relationship the higher the likelihood of a good match. The crucial role of information in the labor market has been recognized since Stigler (1962), but despite a voluminous literature on job matching and organizational behavior in labor markets, we know far less about employers' recruitment strategies than about job seekers' search strategies. As Granovetter (1995, p.155) notes, "while people are finding jobs, employers are finding people to fill them, and their behaviors, strategies, and purposes play a central but often neglected role in the process of matching people to jobs." A dearth of good data describing recruitment decisions likely explains the imbalance in research effort. In this paper I analyze employer recruitment strategies using a unique dataset, the Multi-City Study of Urban Inequality (MCSUI), a cross-sectional telephone survey of 3510 establishments in LA, Boston, Detroit and Atlanta, conducted during $1992-1995$. Employers in the survey were asked questions about the most recently hired worker, including how long it took to hire this worker, the recruitment methods that were used and the one that generated the hire, the worker's starting wage, and the screening methods typically used for hiring workers into that job. ${ }^{1}$

My broad objective in this paper is to provide a framework for analyzing the labor market effects of employer recruitment choice. I propose a dynamic, discrete-choice, structural model in which employers choose recruitment strategies and post wage offers over time in an effort to fill a job vacancy, solving it numerically and estimating its parameters. To my knowledge, this paper is the first to estimate a dynamic structural

\footnotetext{
${ }^{1}$ Telephone screening was used in an effort to identify a respondent who hired the most recently hired worker. The respondent was the owner in $14.5 \%$ of the cases, the manager or supervisor in $42 \%$, a personnel department official in $31.5 \%$, and someone else in $12 \%$. The survey instrument took $30-45$ minutes to administer on the telephone, with a response rate of $67 \%$ for screened interviews. Sampling weights were constructed to correct for the complexities of the sampling scheme, and weighted observations are a representative sample of establishments, such as would occur if a random sample of employed people were drawn from each city. See Holzer (1996) for more information about the data. Descriptive analysis of recruitment methods, starting wages, vacancy duration, and skill levels using these data is found in DeVaro (2005).
} 
model of recruitment choice. ${ }^{2}$ The typical approach taken in previous work is to estimate regressions of some labor market outcome, such as wages or vacancy duration, on a set of explanatory variables including indicators for various recruitment methods, which are assumed exogenous. A structural representation of the employer's recruitment problem is of interest for the usual reasons. In particular, it permits analysis of how labor market outcomes are affected by changes in the economic environment, accounting for the behavioral responses of employers through their recruitment and wage-offer decisions.

Following the tradition since Rees (1966), Rees and Schultz (1970), and the first edition of Granovetter (1995) in 1974, throughout the analysis I distinguish two main recruitment strategies. "Informal methods" involve word-of-mouth referrals from current employees or friends, whereas "formal methods" involve other means of recruitment. Rees (1966) documented the prevalence of informal methods in recruiting blue and white-collar workers in a Chicago-area study and argued that the effectiveness of informal networks was under appreciated. Prior to the work of Rees, the conventional view was that formal methods provided better information than informal methods, thereby contributing to the efficient functioning of the labor market. In counterpoint, Rees and Schultz (1970, p.221) wrote “... we do not feel that this reliance [on informal methods] is necessarily evidence of an imperfect market. Rather it suggests to us the importance of kinds of qualitative information about job seekers and about vacant jobs that could not be communicated well through formal channels, such as newspaper ads and employment agencies..." In highlighting the role of recruitment choices as information-generating devices, Rees and Schultz distinguished between "extensive information", which pertains to the number of job seekers and vacancies covered by the information, and "intensive information", which provides detailed information about specific job seekers or vacancies. Formal recruiting methods such as advertising are effective in generating substantial extensive information, for example a high volume of applicants, but the information about individual applicants is usually quite limited. In

\footnotetext{
${ }^{2}$ Two theoretical papers are worthy of note. In a job search model focusing on jobseekers' search strategies, Mortensen and Vishwanath (1994) considers two distributions of wages, one corresponding to job offers obtained when jobseekers use indirect referrals from an employed friend, and the other from direct application to an employer. Montgomery (1991) imbeds social networks in an adverse selection model to analyze the effects of social networks on labor market outcomes.
} 
contrast, informal methods provide inside information on a small and select group of applicants. Rees and the subsequent literature argued that informal methods can lead to better employment matches by generating more intensive information.

After estimating the parameters of the model, I conduct three counterfactual simulations. The first is a wage subsidy, which increases the attractiveness of hiring a worker, inducing employers to shift their recruitment strategies more in the direction of informal methods and to post higher wage offers, since both responses increase the perperiod probability of a hire. The second is an "information policy" (designed to improve matches for workers hired through formal channels), which creates a shift towards formal recruitment methods, a lower overall starting wage distribution, longer vacancy durations, higher starting wages and shorter vacancy durations for those workers hired via formal methods, and lower starting wages and longer vacancy durations for workers hired via informal methods. The third is an increase in the degree of heterogeneity in the match qualities of prospective hires, which induces substitution from informal to formal methods. Employers who remain with informal methods become more hesitant to raise wage offers during the recruitment campaign (since they are less eager to attract matches of more uncertain quality), whereas those remaining with formal methods become more likely to raise wage offers during the campaign, since the "option value" (which pertains only to workers hired via formal methods) is increasing in the variance of match quality.

For each counterfactual, I decompose the total effects into "pure wage effects" (i.e., changes to observed outcomes that would result if employers were forced to remain with their pre-policy recruitment choice, responding only by modifying their wage offer sequences) and "recruitment-wage effects" (i.e. the change in observed outcomes that occurs since some employers switch recruitment strategies in response, thereby altering the composition of employers - in terms of their chosen wage-offer sequences - who use a given recruitment strategy). The structural approach allows us to quantify the relative importance of these two effects in determining labor market outcomes.

Although the MCSUI data offer a wealth of information concerning employer hiring strategies, some data limitations are worth noting at the outset. First, for each employer all of the information pertains to the most recently hired worker or to the job into which this worker was hired, so we lack information on these employers' hiring 
strategies more generally. Second, the data lack information on both the intensity with which recruitment and screening methods were used and also (when multiple recruitment methods were used) their sequencing. Third, since we do not observe whether the most recent worker was hired alone or with others, I cannot allow for differences in recruitment behavior according to how many workers were desired. The model I propose assumes that a single worker is sought, whereas in the data the most recent hire may in some cases have been part of a broader hiring campaign.

The MCSUI contains quite a heterogeneous set of workers, jobs, and skill levels, while employer recruitment strategies are likely to vary substantially across different types of jobs, even for the same employer. It is not clear that estimating a structural model on a sample that mixes lawyers and bus drivers is a valuable exercise. For that reason, I restrict the analysis to a relatively homogeneous group of workers and jobs, namely those listed as "Administrative Support Occupations, Including Clerical”, which is the largest occupational subsample in the MCSUI. The most recently hired worker was a member of this group in 933 cases, and information on the recruitment method that generated the most recent hire is available for 917 cases. $^{3}$

\section{BASIC EMPIRICAL OBSERVATIONS}

Some basic empirical observations serve as a useful starting point and help to motivate the economic model. I present three of these in Table $1 .^{4}$ First, vacancy durations are shorter when clerical workers are generated by informal methods than by formal methods. The average vacancy duration for secretaries hired through informal

\footnotetext{
${ }^{3}$ These numbers are for positions that do not require a college degree. In the absence of this restriction, the numbers would be 992 and 974, respectively. I drop observations requiring a college degree since such jobs are likely to differ substantially from those that do not require a college degree, though conducting the analysis on the slightly larger sample yields very similar results to those I report in the paper.

${ }^{4}$ I define informal methods as 1 if the employer responded that the recruitment method that generated the most recent hire was either "referrals from current employees" or "referrals from friends", and 0 if the worker was generated via one of the following (formal) methods: newspaper advertisements, help-wanted signs, referrals from state employment agencies, referrals from private employment agencies, referrals from community employment agencies, referrals from school placement officers, referrals from unions, accepting walk-ins, and "other." Vacancy duration (in weeks) is the answer to the following question: "From the time you began recruiting until you hired someone, how long did it take to hire your newest employee?" The starting wage is the real hourly starting wage in 1990 dollars. When asked the starting wage of the most recent hire, about $70 \%$ of employers responded with an hourly wage. The other $30 \%$ reported a weekly, monthly, or annual wage, and these I converted to hourly wages assuming standard work schedules. I deflated all hourly wages to 1990 dollars using the CPI-UX.
} 
methods was 2.6 weeks, versus 3.6 weeks for those hired through formal methods. Second, secretaries hired through informal methods received lower starting wages than those hired through formal methods ( $\$ 7.55$ per hour versus $\$ 8.10$ per hour). These first two basic empirical observations will emerge as predictions of the structural model. Third, informal methods generated smaller applicant pools than formal methods. The average number of workers who applied for the position held by the most recent hire was 26 if the worker was generated by informal methods and 176 if the worker was generated by formal methods. Similarly, the average number of workers who interviewed for the position was 8 in the case of informal methods and 11 in the case of formal methods.

A fourth observation, not reported in Table 1, is that screening of applicants appeared to be less intensive when informal recruiting methods were used than when formal methods were used. Employers were asked how often each of the following 5 screening methods was used for the position into which the most recent worker was hired: personal interviews, tests, reference checks, checks of educational record, and checks of criminal record. Possible responses are: " 3 = always", " $2=$ sometimes" or " $1=$ never." Ordered probits of these outcomes on a dummy for whether the most recent hire was generated by informal methods yield a negative coefficient for informal methods in all 5 models. The employer was also asked whether a test was required for the position and whether a sample of work was required. Probits of these outcomes on an informalmethods dummy yield negative coefficients in both cases. Thus, for all 7 screening methods the point estimates indicate less frequent use of screening for the position into which the most recent worker was hired if the worker was generated via informal methods, though in most cases these differences are statistically insignificant at conventional levels. ${ }^{5}$

Table 2 displays further evidence suggesting the possibility of substitution between informal recruitment methods and intensive screening. The estimates are from ordered probit models in which the dependent variable equals 0 if the employer reported

\footnotetext{
${ }^{5}$ A likely reason that the statistical evidence is not stronger is that all 7 screening questions unfortunately ask about what was done in general for this position, as opposed to what was done in the actual case of the most recent hire. This matters, because employers often use a combination of recruitment methods. Suppose the most recently hired secretary was obtained via informal methods but that the same employer usually generated secretaries via formal methods. Then in response to the questions that ask about what
} 
that recruiting methods for the position into which the most recent worker was hired were less likely to involve informal methods at the time of the survey than 5 to 10 years earlier, 1 if there had been no change in the use of informal methods during the 5 years preceding the survey, and 2 if informal methods were used more often at the time of the survey when recruiting to fill such a position than 5 years earlier. Independent variables are binary indicators for whether particular screening methods were used less often at the time of the survey than 5 to 10 years ago. If there is substitution between informal recruitment methods and the various screening methods, the coefficients in these ordered probit models should be positive. While many of the effects are estimated with low precision, this is indeed the pattern that emerges.

Employers in the economic model are assumed to post wage offers each period, with higher posted wages increasing the per-period hiring probability. ${ }^{6}$ Some offer high wages to lure workers fast, while others offer low wages to reap greater profits per period in the event that a worker is hired. If a recruitment campaign is going badly, some employers might raise the offered wage to increase the hiring probability. However, the data contain only starting wages, not offered wages. Even though the model implies that offered wages are non-decreasing over the duration of the recruitment campaign, the predicted sign of the correlation between vacancy duration and starting wages is ambiguous since high wage offers from the outset are more likely than low wage offers to yield a short duration. If a high starting wage is observed in the data, there is no way to determine whether that employer's offered wage was high from the outset of the campaign, or if it started low and was raised later. Employers who offer high wages from the outset are likely to experience shorter vacancy durations than those who start out with low wage offers and later switch to high wage offers.

The point is that in a regression of vacancy duration on starting wages, a positive slope coefficient provides no evidence in favor of a wage-posting model or against it. If we restrict our attention to the subsample of employers who hired someone very quickly, however, then offered wages are essentially the same as starting wages, since few if any employers would have increased their wage offer in such a short time. In contrast, the

screening was typically done for this position, the employer would respond based on a screening strategy for an applicant pool usually generated via formal methods.

${ }^{6}$ This is also the case in the model of Albrecht et al. (2006). 
full sample will contain many employers who raised their wage offer at some point(s) during the recruitment campaign. So a wage-posting model does imply that if we estimate such a regression on successive subsamples (i.e. workers hired within the first two weeks, within the first three weeks, within the first four weeks, and so on) the slope coefficient should increase with the sample size. Figure 1 supports this hypothesis, and as seen in Figure 2, even after controlling for whether the position requires a college degree, whether the firm is a franchise, the fraction of unionized employment, establishment size, number of sites of operation, and 8 industry indicators, the graph is still increasing. ${ }^{7}$ This pattern is consistent with the wage-posting model I present in the next section. Furthermore, some alternative theories for the process generating starting wages - such as ex-post bargaining - would not have this pattern. Nonetheless, the increasing pattern might also reflect unobserved heterogeneity in posted vacancies.

\section{AN ECONOMIC MODEL OF EMPLOYER RECRUITMENT CHOICE}

I model the problem an employer faces in filling a single vacancy. The basic framework is a search model in which the employer commits to a recruitment strategy at the outset of a three-period recruitment campaign and posts wage offers at the start of each period, until a hire occurs, to maximize expected profit. ${ }^{8}$ I treat the jobseeker side of the labor market as exogenous. At the start of the first period the employer chooses one of two recruitment strategies, (either "informal methods", denoted I, or "formal methods", denoted F), and simultaneously posts either a high wage offer, $\mathrm{W}_{\mathrm{H}}$, or a low wage offer, $\mathrm{W}_{\mathrm{L}}$. In each period for which the position remains vacant, a hire occurs with probability $\mathrm{p}_{\mathrm{I}}(\mathrm{w})$ if informal methods were chosen and with probability $\mathrm{p}_{\mathrm{F}}(\mathrm{w})$ if formal methods were chosen, where $p_{j}(w)=p_{j H}$ if $w=W_{H}$, and $p_{j}(w)=p_{j L}$ if $w=W_{L}$, for $j=I, F$. Informal methods yield greater hiring probabilities, as do higher wage offers. Thus, I

\footnotetext{
${ }^{7}$ Figures 1 and 2 use the full MCSUI sample, though restricting the sample to clerical workers yields the same pattern of results.

${ }^{8}$ A three-period formulation allows for a simple estimation scheme, by maintaining a small number of discrete outcomes, while adequately capturing the dynamics of the economic problem. The data reveal that most recruitment campaigns last only a few weeks. As a practical matter, employers do not continuously change offered wages during this time. The three-period formulation allows an initial wage offer and two opportunities to adjust the offer as the recruitment campaign progresses.
} 
assume $\mathrm{p}_{\mathrm{F}}\left(\mathrm{W}_{\mathrm{L}}\right)<\left\{\mathrm{p}_{\mathrm{F}}\left(\mathrm{W}_{\mathrm{H}}\right)\right.$ and $\left.\mathrm{p}_{\mathrm{I}}\left(\mathrm{W}_{\mathrm{L}}\right)\right\}<\mathrm{p}_{\mathrm{I}}\left(\mathrm{W}_{\mathrm{H}}\right) .{ }^{9}$ I impose no ordering on $\mathrm{p}_{\mathrm{F}}\left(\mathrm{W}_{\mathrm{H}}\right)$ and $\mathrm{p}_{\mathrm{I}}\left(\mathrm{W}_{\mathrm{L}}\right)$. If a hire does not occur in the first period, the employer can post a new wage offer at the start of periods 2 and 3, though the original recruitment choice remains fixed. ${ }^{10}$ This assumption is reasonable for the relatively short recruitment campaigns that are observed for the vast majority of clerical workers in these data. In a typical case, organizations have established procedures for recruiting new secretaries. A salary range is often posted. The chosen recruitment strategies generate a flow of applicants and interviews over time. The model captures the idea that when the campaign does not end quickly the employer (or HR department) becomes more likely to offer a wage towards the higher end of the range.

Once hired, a worker remains with the employer through the end of the third period, and profits are normalized to zero thereafter. ${ }^{11}$ Let $\theta_{\mathrm{I}}$ and $\theta_{\mathrm{F}}$ denote non-negative,

\footnotetext{
${ }^{9}$ The assumption that, for a given wage offer, informal methods yield greater hiring probabilities than formal methods is motivated by the empirical evidence in Section II that vacancy durations are shorter when workers are generated by informal methods than by formal methods. A natural interpretation, suggested by the evidence in Section II, is that formal methods take longer to generate applicants and that time must be invested in intensive screening of an applicant pool that is larger and of lower average quality than one generated via informal methods.

${ }^{10}$ An alternative assumption is that employers begin with informal methods, turning to formal methods only if informal methods fail. Employers may have a stock of "search capital" (i.e. a stock of phone calls they can make) which they exhaust before resorting to formal methods that are costlier than informal methods in some dimension. To fully address this idea would require data on the sequencing of the chosen recruitment methods. While such data are lacking in the MCSUI, the combination of data on chosen recruitment methods in conjunction with the methods that actually generated the worker allows me to produce some basic empirical facts that seem inconsistent with this alternative explanation.

First, if we consider the subsample of secretaries from the analysis sample that were generated via formal methods, the fraction of these recruitment campaigns for which informal recruitment methods were also chosen (even though they failed to generate the hire) should be 100 percent if the alternative explanation is correct. In fact it is under 79 percent, indicating that in a non-trivial fraction of cases (over 20 percent) the employer relied exclusively on formal methods from the outset, without even attempting to draw down a stock of "search capital" by soliciting informal referrals from current employees and friends. In the other cases, we know nothing about the sequencing, so it might be that informal methods are chosen first, and it might not.

Second, if we look at the entire analysis sample of 770 on which the structural model is estimated, the fraction of secretaries generated via formal methods is 0.666 . Now, if we further restrict the sample to the 591 observations for which both informal and formal methods were both chosen in the campaign, then (according to the alternative explanation) we should see that the fraction of secretaries ultimately generated via formal methods far exceeds 0.666 . This is because, according to the alternative argument, the employer only switches to formal methods once it becomes clear that informal methods are not working, so conditional on the event that the employer switches to formal methods the probability that the hire will ultimately be generated via formal methods should be extremely high. In fact, it remains exactly 0.666 .

${ }^{11}$ An alternative assumption would be that, once hired, a worker remains with the employer forever. Much of the analysis (including Propositions 1 and 2 describing employer behavior) remains unchanged under this alternative assumption, though the empirical model under this alternative assumption does not fit the data quite as well as the model under the assumption in the present analysis.
} 
continuously-distributed, stochastic match qualities of workers from the applicant pools generated by informal methods and formal methods, respectively. The moments of $\theta_{\mathrm{I}}$ and $\theta_{\mathrm{F}}$ are assumed to exist. The employer observes the distributions from which $\theta_{\mathrm{I}}$ and $\theta_{\mathrm{F}}$ are drawn (both lognormal in the empirical work) but never observes the realized values of these match qualities. Hence, there is no basis for employer-induced separations, and negative realized profits are possible, though I assume the expected profit from searching is positive whenever a vacancy exists. ${ }^{12}$ There are no separations in the model. ${ }^{13}$

In the spirit of Rees (1966) and the subsequent literature, I assume that (prior to screening of applicants) informal methods yield better matches, on average, than formal methods, so that $\mathrm{E}\left(\theta_{\mathrm{I}}\right)=\mu>\mathrm{E}\left(\theta_{\mathrm{F}}\right)=1$, though $\operatorname{Var}\left(\theta_{\mathrm{I}}\right)=\operatorname{Var}\left(\theta_{\mathrm{F}}\right)$. Formal methods, on the other hand, generate large applicant pools to which intensive screening methods are then applied, as suggested by the basic empirical observations in Section II. I model this increased selectivity from a larger applicant pool by allowing an employer using formal methods to take the best of two draws from a two-applicant pool, given that a hire occurs in that period. While the employer never observes realized match qualities, if formal methods are chosen he observes which of the two draws for the prospective hires is larger. ${ }^{14,15}$

\footnotetext{
${ }^{12}$ Sufficient conditions to ensure that this condition always holds in the empirical analysis are provided at the end of the first paragraph of Section IV.

${ }^{13}$ An extension of the model to incorporate exogenous separations would be straightforward. Since the sample I use to estimate the model consists of the most recently hired worker at each establishment, relatively few separations are observed.

${ }^{14}$ Note that I assume $\mathrm{E}\left[\theta_{\mathrm{I}}\right]>\mathrm{E}\left[\theta_{\mathrm{F}}\right]$ rather than $\mathrm{E}\left[\theta_{\mathrm{I}}\right]>\mathrm{E}\left[\theta_{\mathrm{F}(2)}\right]$, where $\theta_{\mathrm{F}(2)}$ denotes the second order statistic based on two draws from the distribution of $\theta_{\mathrm{F}}$. Thus, the assumption is that on a pre-screening basis, informal methods yield higher-quality matches on average than formal methods. But the larger applicant pool associated with formal methods allows intensive screening (modeled as taking the maximum of two draws). If the alternative inequality were imposed instead, the firm would always choose informal methods, and the model could not be estimated.

${ }^{15}$ The assumption of common variance in the (pre-screening) match quality distributions is not as restrictive as it might appear. Note that the post-screening match quality distributions, which are the ones relevant to the hiring decision and to estimation, are such that the one for formal methods has a lower variance (due to sampling the second order statistic) than the one for informal methods. Thus, the key assumption is merely that, after screening, match qualities are lower variance for formal methods than for informal. This seems plausible, particularly given the descriptive evidence from Section II suggesting that employers screen secretaries more intensively when they recruit using formal methods. The point is that while relying on someone's informal recommendation might be quite informative, it is generally less informative than testing potential hires yourself in an interview (particularly in the context of secretaries). One could imagine an alternative set of assumptions on the variances of the pre-screening match quality distributions that would be compatible with assumptions I have made on the post-screening match quality distributions, since it is only the latter distributions that are relevant to the estimation.
} 
Once hired, in each period of employment the worker receives the wage offered in the hiring period and produces net revenue of $\left(\mathrm{M} \theta_{\mathrm{I}}\right)^{\gamma}$ if hired via informal methods and $\left(\mathrm{M} \theta_{\mathrm{F}(2)}\right)^{\gamma}$ if hired via formal methods, where $\mathrm{M} \geq 1$ denotes the deterministic component of the labor input, $\theta_{\mathrm{F}(2)}$ denotes the second order statistic based on two draws from the distribution of $\theta_{\mathrm{F}}$, and $\gamma$ is a parameter between 0 and 1 that has density $\mathrm{g}(\gamma)$ in the population of employers. ${ }^{16}$ Thus, while it is the expectation of a concave function of $\theta_{\mathrm{I}}$ that is the relevant consideration when choosing informal methods, it is the expectation of a concave function of $\theta_{\mathrm{F}(2)}$ that is relevant when choosing formal methods. I also assume $\mathrm{E}\left(\theta_{\mathrm{I}}\right)^{\gamma}>\mathrm{W}_{\mathrm{L}} / \mathrm{M}^{\gamma} \forall \gamma$, so that for all employers, choosing informal methods and a low wage offer guarantees positive expected profit from searching in each period for which a vacancy exists.

Formally, let $\mathrm{j}$ denote an index of the recruitment strategies (I and F), $\mathrm{T}$ the number of periods (i.e. $\mathrm{T}=3$ ), $\beta$ the one-period discount factor, and $\chi_{\mathrm{I}}(\mathrm{j})$ an indicator function equaling 1 if $j=I$ and 0 if $j=F$. I denote each branch of the value function, $V$, as $\mathrm{V}_{\mathrm{t}}^{\mathrm{j}}$, for $\mathrm{t}=1,2,3$ and $\mathrm{j}=\mathrm{I}, \mathrm{F}$. Thus, $\mathrm{V}=\max \left[\mathrm{V}_{1}{ }^{\mathrm{I}}, \mathrm{V}_{1}{ }^{\mathrm{F}}\right]$, where

$$
\begin{array}{ll}
V_{t}^{j}=\max _{w}\left[p_{j}(w) \sum_{k=0}^{T-t} \beta^{k}\left[\chi_{I}(j) E\left(M \theta_{I}\right)^{k}+\left(1-\chi_{I}(j)\right) E\left(M \theta_{F(2)}\right)^{k}-w\right]+\right. & \text { if } \mathrm{t} \leq \mathrm{T} \\
\left.\left(1-p_{j}(w)\right) \beta V_{t+1}^{j}\right]^{2} & \text { if } \mathrm{t}>\mathrm{T}
\end{array}
$$

I compute the solution to the employer's problem numerically via backward induction.

The following two propositions describe employer behavior (see Appendix A for proofs):

Proposition 1: Let $\mathrm{j}$ and $\mathrm{t}$ index recruitment strategies and periods. Given the parameters and the choice of recruitment strategy $\mathrm{j}$, there exist thresholds, $\gamma_{\mathrm{jt}}$, in $[0,1]$, such that in period $t$, employer i posts a wage offer of $\mathrm{W}_{\mathrm{H}}$ if $\gamma_{\mathrm{i}}>\gamma_{\mathrm{jt}}$ and a wage offer of $\mathrm{W}_{\mathrm{L}}$ if $\gamma_{\mathrm{i}}<\gamma_{\mathrm{jt}}$, and these thresholds are such that $0 \leq \gamma_{\mathrm{j} 3} \leq \gamma_{\mathrm{j} 2} \leq \gamma_{\mathrm{j} 1} \leq 1$. If and only if the parameters are such that $0<\gamma_{\mathrm{j} 3}<\gamma_{\mathrm{j} 2}<\gamma_{\mathrm{j} 1}<1$ for recruitment strategy $\mathrm{j}$, then each of the four possible wage-offer sequences - i.e. $\left(\mathrm{W}_{\mathrm{L}}, \mathrm{W}_{\mathrm{L}}, \mathrm{W}_{\mathrm{L}}\right),\left(\mathrm{W}_{\mathrm{L}}, \mathrm{W}_{\mathrm{L}}, \mathrm{W}_{\mathrm{H}}\right),\left(\mathrm{W}_{\mathrm{L}}, \mathrm{W}_{\mathrm{H}}, \mathrm{W}_{\mathrm{H}}\right),\left(\mathrm{W}_{\mathrm{H}}, \mathrm{W}_{\mathrm{H}}, \mathrm{W}_{\mathrm{H}}\right)$ - could occur in the labor market if recruitment strategy $\mathrm{j}$ is chosen.

Proposition 2: Recruitment strategy $\mathrm{j}$ is said to be potentially observable in the labor market if and only if the parameters of the model are such that $\operatorname{Prob}(\gamma \in\{\gamma$ : employer chooses recruitment strategy $\mathrm{j}\})>0$. Let $\gamma_{\text {IFk }}^{*}$ denote the $\mathrm{k}^{\text {th }}$ threshold value of $\gamma$ such that there exist non-negative $\varepsilon_{1}$ and $\varepsilon_{2}$ such that employer i chooses informal methods if $\gamma_{i} \in$ $\left\{\gamma: \gamma_{\mathrm{IFk}}^{*}-\varepsilon_{1}<\gamma<\gamma_{\mathrm{IFk}}^{*}\right\}$, formal methods if $\gamma_{\mathrm{i}} \in\left\{\gamma: \gamma_{\mathrm{IFk}}^{*}<\gamma<\gamma_{\mathrm{IFk}}^{*}+\varepsilon_{2}\right\}$, and is indifferent between the two methods if $\gamma_{\mathrm{i}}=\gamma_{\text {IFk }}$. Similarly, let $\gamma_{\text {FIk }}^{*}$ denote the $\mathrm{k}^{\text {th }}$ threshold value of $\gamma$ such that there exist non-negative $\varepsilon_{1}$ and $\varepsilon_{2}$ such that employer $\mathrm{i}$

\footnotetext{
${ }^{16}$ Employer heterogeneity in this model is captured by $\gamma$. A central question in the literature on job search and wage-posting games is whether the wage distribution implied by the economic model is nondegenerate and what mechanism generates wage dispersion. In this model, employer heterogeneity in $\gamma$ implies dispersion in the equilibrium distribution of starting wages.
} 
chooses formal methods if $\gamma_{\mathrm{i}} \in\left\{\gamma: \gamma_{\text {FIk }}^{*}-\varepsilon_{1}<\gamma<\gamma_{\text {FIk }}^{*}\right\}$, informal methods if $\gamma_{\mathrm{i}} \in\{\gamma$ : $\left.\gamma_{\text {FIk }}^{*}<\gamma<\gamma_{\text {FIk }}^{*}+\varepsilon_{2}\right\}$, and is indifferent between the two methods if $\gamma_{i}=\gamma_{\text {FIk }}^{*}$. Then, given the parameters of the model, the following statements describe employer recruitment behavior:

1) For every value of $\gamma$ in the interval $[0,1]$, either the employer chooses informal methods, or formal methods, or is indifferent between the two methods.

2) Either formal methods are the only potentially observable strategy in the labor market, or informal methods are the only potentially observable strategy, or formal and informal methods are both potentially observable. Furthermore, the parameters of the model are such that both recruitment strategies are potentially observable if and only if there exists at least one threshold of type $\gamma_{\text {IFk }}^{*}$ or of type $\gamma_{\text {FIk }}^{*}$ in the interval $(0,1)$.

3) If both recruitment methods are potentially observable in the labor market, the set of all thresholds of type $\gamma_{\text {IFk }}^{*}$ or $\gamma_{\text {FIk }}^{*}$ partitions the interval $[0,1]$ into subintervals that alternate between the two methods.

Proposition 1 says that the sequence of posted wage offers is non-decreasing for either recruitment strategy and that the 3 thresholds $\gamma_{\mathrm{jt}}$ partition the interval $[0,1]$ into 4 regions corresponding to the 4 possible wage-offer sequences given recruitment choice $\mathrm{j}$. As the degree of concavity in the production function decreases, employers are more willing to post high wage offers earlier in the recruitment campaign. Intuitively, since expected revenue given that a hire occurs is monotonically increasing in $\gamma$ for either recruitment strategy, as $\gamma$ increases employers are increasingly eager to fill the position, and since the recruitment strategy is fixed once it is chosen, they can raise the per-period hiring probability only by posting higher wage offers. Proposition 2 says that every employer-type chooses to search and that the $[0,1]$ interval can, as long as at least one $\gamma^{*}$ threshold lies in $(0,1)$, be partitioned into regions of $\gamma$ that alternate between the two recruitment strategies as $\gamma$ increases from 0 to 1 . Note that Proposition 1 does not say that if $0<\gamma_{\mathrm{j} 3}<\gamma_{\mathrm{j} 2}<\gamma_{\mathrm{j} 1}<1$ then all 4 possible wage sequences could potentially be seen in the labor market. As the last phrase of Proposition 1 indicates, that is true only if recruitment strategy $\mathrm{j}$ is chosen, meaning (given the result in Proposition 2) that each of $\gamma_{\mathrm{j} 3}, \gamma_{\mathrm{j} 2}$, and $\gamma_{\mathrm{j} 1}$ lies in $\mathrm{a} \gamma^{*}$-interval for which recruitment strategy $\mathrm{j}$ is the optimal choice.

Exogenous policy or environmental changes that affect the parameters of the model potentially change both the $\gamma^{*}$ thresholds and the $\gamma_{\mathrm{jt}}$ thresholds, thereby altering both the chosen recruitment strategy and the chosen wage-offer sequence (given the recruitment choice) for the employer. This suggests that the total effect of a policy on observed outcomes (such as the distributions of starting wages and vacancy duration) can 
be decomposed into two effects. The first I call the "pure wage effect", which is the change to observed outcomes that would occur if employers were forced to remain with their original (pre-policy) recruitment choice, thereby responding to the policy only by modifying wage-offer sequences. The second I call the "recruitment-wage effect", which is the change to observed outcomes that occurs since some employers switch recruitment strategies in response to the policy change, thereby altering the composition of employers (in terms of their chosen wage-offer sequences) who use a given recruitment strategy. The wage effect is the change in the distributions of observed outcomes resulting from changes in the thresholds $\gamma_{\mathrm{F} 3}, \gamma_{\mathrm{F} 2}, \gamma_{\mathrm{F} 1}, \gamma_{\mathrm{I} 3}, \gamma_{\mathrm{I} 2}$, and $\gamma_{\mathrm{I} 1}$, holding the $\gamma^{*}$ thresholds fixed. The recruitment-wage effect results from changes in the $\gamma^{*}$ thresholds.

The decomposition illustrates the point that endogenous changes in recruitment strategies in response to changes in the economic environment have implications for the distributions of starting wages and vacancy duration. The magnitudes of the shifts in wage-offer sequences and recruitment strategies depend on the distribution of employer types, in particular the concentration of "marginal" employers that have values of $\gamma$ in the neighborhood of the various $\gamma_{\mathrm{jt}}$ or $\gamma^{*}$ thresholds. The greater the concentration of such employers the greater the magnitude of the shifts in observed outcomes that occur following a change in the economic environment. This density of employer types, $\mathrm{g}(\gamma)$, is determined by the parameters $\alpha_{\gamma}$ and $\beta_{\gamma}$. In Section V, I consider three counterfactual simulations to illustrate the decomposition of total effects into wage effects and recruitment-wage effects.

\section{IDENTIFICATION AND ESTIMATION OF THE EMPIRICAL MODEL}

The identification problem is to infer from a joint distribution of recruitment choices, starting wages, and vacancy durations a joint distribution of match quality and employer heterogeneity parameters plus per-period hiring probabilities. The sources of identification include the cross-sectional, retrospective variation observed in the data, along with the distributional assumptions (including independence of all the stochastic components) and the various assumptions of the economic model. I assume that the match qualities, $\theta_{\mathrm{I}}$ and $\theta_{\mathrm{F}}$, are distributed lognormal with means of $\mathrm{E}\left(\theta_{\mathrm{F}}\right)=1$ and $\mathrm{E}\left(\theta_{\mathrm{I}}\right)=$ $\mu>1$ and a common variance of $\sigma^{2}$. I assume that $\gamma_{i}$, the employer-type parameter for 
establishment $i$, is a draw from the beta distribution with (positive) shape parameters $\alpha_{\gamma}$ and $\beta_{\gamma}{ }^{17}$ I fix values for $\mathrm{W}_{\mathrm{H}}$ and $\mathrm{W}_{\mathrm{L}}$. Earnings over a 3-week period based on a 40-hour week and a wage of $\$ 9.42$ per hour (roughly the $75^{\text {th }}$ percentile of the starting wage distribution) are $\$ 1130.40$. The same calculation based on a wage of $\$ 6.27$ per hour (roughly the $25^{\text {th }}$ percentile of the starting wage distribution) yields $\$ 740.40$. Scaling both by dividing by 1000 yields $\mathrm{W}_{\mathrm{H}}=1.1304$ and $\mathrm{W}_{\mathrm{L}}=0.7404$. Given the assumptions $\theta_{\mathrm{I}} \sim \mathrm{LN}\left(\mu, \sigma^{2}\right), \mu>1, \mathrm{M} \geq 1$, and $\mathrm{W}_{\mathrm{L}}<1$, unless $\sigma$ is extremely large the condition ensuring that employers can make positive expected profit from searching (by choosing informal methods and a low wage offer) holds for all values of $\gamma$. More precisely, as shown in Appendix A, the condition is $\sigma<\mu[\exp (\mathrm{m})-1]^{1 / 2}$, where $\mathrm{m}=$ $2 \ln \left((\mathrm{M} \mu)^{\gamma} / \mathrm{W}_{\mathrm{L}}\right) /[\gamma(1-\gamma)]$. This constraint on $\sigma$ is not binding in the estimation.

Let $\xi$ denote the $9 \times 1$ vector of parameters to be estimated, i.e. $\xi^{\prime}=\left[M, \alpha_{\gamma}, \beta_{\gamma}, \mu\right.$, $\left.\sigma, \mathrm{p}_{\mathrm{IH}}, \mathrm{p}_{\mathrm{IL}}, \mathrm{p}_{\mathrm{FH}}, \mathrm{p}_{\mathrm{FL}}\right]$. The moments from the data that help to identify each parameter are the observed frequencies of the 14 possible outcomes implied by the economic model: 3 hiring periods $\times 2$ recruitment strategies $\times 2$ wage levels +2 ways in which the vacancy could remain unfilled by the end of the third period. These frequencies are displayed in Table 4. If the most recently hired worker was hired in 0 to 3 weeks I define the hire as occurring in period 1. Periods 2 and 3 correspond to hiring times of 4 to 6 weeks and 7 to 9 weeks, respectively. ${ }^{18}$ I define the recruitment strategy as "informal" if the most recent hire was generated either by referrals from current employees or by referrals from friends; otherwise it is "formal." If the starting wage is above (below) the median of $\$ 7.46$ per hour I define the starting wage as "high" ("low").

A simple way to illustrate which moments from the data help to identify each parameter is via comparative statics exercises that plot the changes in the simulated

\footnotetext{
${ }^{17}$ As an alternative distributional assumption, I also tried $\gamma_{\mathrm{i}}=\Phi\left(\mathrm{x}_{\mathrm{i}}\right)$, where $\mathrm{x}_{\mathrm{i}} \sim \mathrm{N}\left(\mu_{\gamma}, \sigma_{\gamma}{ }^{2}\right)$ and $\Phi$ is the standard normal cdf. I found results roughly similar to those I report here. In particular, the distribution of employer types was "U-shaped" with a lot of mass concentrated in the extremes of the $[0,1]$ interval, particularly near 0 . The fit of the model was slightly worse using this alternative distributional assumption, as gauged by chi-square tests of goodness-of-fit; the minimized distance function was 0.0024 , as opposed to 0.0023 for the results reported here using the beta distribution.

${ }^{18}$ The survey question asks the employer how many weeks it took "from the time you began recruiting until you hired someone" to hire the most recently hired worker. Since a hire occurred in all cases the data are a sample of completed recruitment spells. Note that because the sample is one of completed spells as opposed to current and completed spells, no problems of length-biased sampling arise given that
} 
distributions of recruitment strategies, starting wages, and vacancy durations that result from varying one of the parameters while fixing the others. I do this using 10,000 draws and a window of plus or minus 2 percent of the original value for the parameter being varied. This window is small enough that the hiring probabilities retain the correct ordering and all lie between 0 and 1 , and $\mathrm{E}\left(\theta_{\mathrm{I}}\right)>\mathrm{E}\left(\theta_{\mathrm{F}}\right)$. Since I vary each parameter from its estimated value, holding the other parameters fixed at their estimated values, for the purpose of this discussion I take the parameter estimates in Tables 3 as given (as well as Tables 4 and 5, and Figure 3, all of which are implied by the estimates in Table 3). Later in the section I explain the estimation procedure and discuss the resulting estimates. I now summarize the comparative statics results which, since they are based on the estimated parameters, should be viewed as specific to this choice of parameter values, though they may in fact be more general. ${ }^{19}$

The percentage of employers choosing informal recruitment methods is decreasing in the employer-type parameter $\alpha_{\gamma}$, whereas the percentage starting at the high wage is increasing in $\alpha_{\gamma}$. Thus, comparing establishments with informal methods and high starting wages to those with formal methods and low starting wages aids in the identification of $\alpha_{\gamma}$. The three vacancy duration variables do not vary monotonically with $\alpha_{\gamma}$, and therefore observed variation in these variables does not contribute to identification of $\alpha_{\gamma}$. To see why the percent using informal recruitment methods helps to identify $\alpha_{\gamma}$, note that a beta distribution with shape parameters $\alpha_{\gamma}<\beta_{\gamma}<1$ is U-shaped but asymmetric, with more of the mass located near 0 than 1 , and that it becomes more symmetric as $\alpha_{\gamma}$ increases, until it reaches symmetry about $1 / 2$ when $\alpha_{\gamma}=\beta_{\gamma}<1$. Note also that when $\alpha_{\gamma}<\beta_{\gamma}=1$ the distribution is monotonically decreasing, rather than U-shaped, on $[0,1]$, and that is nearly the case in the histogram for $\gamma$ in Figure 3, since the estimate of $\beta_{\gamma}$ exceeds 0.96 . As revealed by the implied $\gamma^{*}$ thresholds in the first column of Table 5 , very high (low) values of $\gamma$ imply that formal (informal) methods are chosen. Thus, holding the other parameters constant, as $\alpha_{\gamma}$ increases the probability mass in the neighborhood of $\gamma=0$ decreases, resulting in substitution from informal to formal methods. The intuition for the relationship between $\alpha_{\gamma}$ and the percentage starting at the

stationarity is assumed. The bulk of the recruitment campaigns were completed in 9 weeks or less. Using 4-week periods instead of 3-week periods yields similar results.

${ }^{19}$ The full set of plots is available from the author upon request. 
high wage is similar. Holding the other parameters constant, increasing $\alpha_{\gamma}$ implies higher values of $\gamma$, on average, which increases the fraction of employers with values of $\gamma$ exceeding the $\gamma$-thresholds in the first column of Table 5 that define cutoffs for wage offers, given the recruitment choice.

Similar reasoning applies to $\beta_{\gamma}$, the second of the two shape parameters in the beta distribution of employer types. The percent using informal methods is increasing and the percent starting at the high wage is decreasing in $\beta_{\gamma}$, where as the hiring durations do not vary monotonically with $\beta_{\gamma}$. As mentioned, when $\beta_{\gamma}$ increases to a value equal to or greater than 1 while the other parameters remain fixed, the distribution of $\gamma$ changes from an asymmetric U-shape to monotonically decreasing, so the probability mass in the neighborhood of 1 decreases. Since the highest values of $\gamma$ are associated with formal methods, such a change generates substitution from formal to informal methods. Similarly, the change decreases the fraction of employers with values of $\gamma$ exceeding the $\gamma$-thresholds in the first column of Table 5 that define cutoffs for wage offers, given the recruitment choice, so the percent starting at the high wage diminishes.

Increases in $\mathrm{M}$, the deterministic component of the labor input, imply increases in the percent using informal methods, the percent starting at the high wage, and the percent hired in the first period, and decreases in the percent hired in period 2 and the percent hired in period 3. These patterns are easily understood given that higher values of $M$ increase per-period profit given that a hire occurs. This increases the relative attractiveness of informal methods and high wage offers, both of which yield faster hires.

Increases in $\sigma$, the standard deviation of the (pre-screening) match quality distributions, imply decreases in the percent using informal methods, the percent starting at the high wage, and the percent hired in the first period, and increases in the percent hired in period 2 and the percent hired in period 3. To see why variation in recruitment methods helps to identify this parameter, note that if the match quality distributions become degenerate the employer would always choose informal methods (since perperiod hiring probabilities are greater and since $\mathrm{E} \theta_{\mathrm{I}}>\mathrm{E} \theta_{\mathrm{F}}$ ). The benefits to the employer of using formal methods increase in $\sigma$ since the expected value of the second order statistic is increasing in the variance of the underlying random variable. This explains why increases in $\sigma$ imply decreases in the percent using informal methods. 
Increases in $\mu$, the mean of $\theta_{\mathrm{I}}$, imply increases in the percent using informal methods, the percent starting at the high wage, and the percent hired in period 1, and decreases in the percent hired in period 2 and the percent hired in period 3. Since an increase in $\mu$ amounts to an increase in the average match quality of workers hired via informal methods (leaving unchanged the average match quality of workers hired via formal methods) it is expected that the percent using informal methods is increasing in $\mu$.

Finally, the per-period hiring probabilities $\left(\mathrm{p}_{\mathrm{IH}}, \mathrm{p}_{\mathrm{IL}}, \mathrm{p}_{\mathrm{FH}}, \mathrm{p}_{\mathrm{FL}}\right)$ display the obvious patterns. That is, an increase in one of the hiring probabilities pertaining to informal (formal) methods raises the percent hired via informal (formal) methods, and an increase in one of the hiring probabilities pertaining to the high (low) wage offer increases (decreases) the percent starting at the high wage.

While the preceding discussion helps to illustrate the mechanics of the model, the parameter values are changed ceteris paribus and, thus, the comparative statics exercises are not fully convincing about the joint identification of all the structural parameters. Therefore, I now discuss the results of some Monte-Carlo experiments in which all parameters are allowed to vary. Given the parameter estimates in Table 3, I generated 100 data sets (each of size 5000) and estimated the model on each data set. For each of the 100 resulting vectors of parameter estimates, I then generated one data set based on the estimated parameters and another data set based on the estimated parameters (but increasing parameter $\mathrm{j}$ by 2 percent), computing the resulting change in the percent using informal recruiting methods, the percent starting at the high wage, the percent hired in period 1 , the percent hired in period 2, and the percent hired in period $3 .{ }^{20}$ I repeated this process for each of the 9 parameters, using data sets of size 10,000 in all cases.

Table 6 summarizes the results. In cell ij, the entry in the first line gives the average (across the 100 Monte Carlo replications) of the marginal effect of a 2 percent increase in parameter (row) $i$ on moment (column) $j$, whereas the entry in the last line (in italics) gives the analogous marginal effect based on the parameter estimates from Table 3 that were derived using the real data. ${ }^{21}$ All reported numbers are multiplied by 100 for easier reading. In most cases the mean marginal effect across the Monte Carlo

\footnotetext{
${ }^{20}$ Results were similar using 1 percent increases instead of 2 percent increases.

${ }^{21}$ Also, the median and standard deviation of the marginal effects across the 100 Monte Carlo replications are in brackets and parentheses, respectively.
} 
replications is roughly similar to the marginal effect based on the parameter estimates derived from the real data, and both are generally consistent with the plots underlying the comparative statics exercises previously summarized. The sign differs between the marginal effect from the real data and the average marginal effect across the Monte Carlo experiments only in one case (the marginal effect of $\alpha_{1}$ on the percent hired in period 3 ), and here it should be recalled that in the preceding discussion of the comparative statics exercises it was noted that this parameter was related to variation in the percent using informal methods and the percent starting at the high wage but not to the duration variables.

In summary, while the discussion of comparative statics held each of the other 8 parameters constant while considering the marginal effect of parameter $\mathrm{j}$, the Monte Carlo exercises reveal that those results are not sensitive to the particular configuration of the other 8 parameters, since the results are generally similar when averaged across many alternative configurations of the other 8 parameters.

\section{Estimation Strategy}

I estimate the parameters by the method of simulated moments. Let $\pi$ be a 13dimensional vector of linearly independent cell frequencies observed in the data (computed using sampling weights), and let $\pi_{\mathrm{s}}(\xi)$ be the corresponding vector of simulated cell frequencies predicted by the economic model. Given an initial parameter vector $\xi_{0}$, I first generate an employer type by taking a pseudo-random draw from the distribution of $\gamma$. I then solve the value function by backward induction to compute the employer's optimal recruitment strategy and wage-offer sequence. Since the stochastic match qualities are unobserved by the employer, decisions are based only on moments of their probability distribution rather than on realized values of match quality. Given the optimal recruitment choices and wage-offer sequences, the hiring probabilities are known. To determine whether a worker is hired in a given period, I generate a pseudorandom draw from the uniform [0,1] distribution. If the draw is less than the relevant hiring probability a worker is assumed to be hired in that period. Thus, combining the employer's optimal choices with the stochastic hiring process, I assign this simulated observation to the appropriate cell. Using the same $\boldsymbol{\xi}_{\mathbf{0}}$, the process is repeated 999 times 
to produce the empirical frequency for each cell. The $\mathrm{k}^{\text {th }}$ element of $\pi_{\mathbf{s}}(\xi)$ is the fraction of simulated observations that fall into the $\mathrm{k}^{\text {th }}$ cell. The distance function to be minimized is $\mathrm{Q}=\left(\pi-\pi_{\mathbf{s}}(\xi)\right)^{\prime} \mathbf{M}\left(\pi-\pi_{\mathbf{s}}(\xi)\right)$, where the optimal weighting matrix, $\mathbf{M}$, is: ${ }^{22}$ $\mathbf{M}=\left[\left(\frac{N}{\left(\sum_{j=1}^{N} \omega_{j}\right)^{2}} \sum_{i=1}^{N} \omega_{i}^{2}\left(\delta_{i}-\pi\right)\left(\delta_{i}-\pi\right)^{\prime}\right]^{-1}\right.$

where $\delta_{\mathrm{i}}=\left[\delta_{1 \mathrm{i}}, \delta_{2 \mathrm{i}}, \ldots, \delta_{13 \mathrm{i}}\right]^{\prime}, \delta_{\mathrm{ki}}=1$ if the $\mathrm{i}^{\text {th }}$ observation in the data is in cell $\mathrm{k}$ and 0 otherwise, sampling weights are denoted by $\omega$, and the sample size is $N=770 .^{23}$ An attractive feature of the optimal weighting matrix is that it is fixed, rather than a function of $\xi$, and this facilitates estimation. ${ }^{24}$

Table 3 displays the parameter estimates, and Table 4 displays information on goodness of fit. Under the null that the data were generated by the economic model, the statistic $0.5 \times \mathrm{Q} \times \mathrm{N}$ is asymptotically distributed as chi-square with degrees of freedom (n-

${ }^{22}$ Define the normalized sampling weight, $\omega_{\mathrm{i}}{ }^{*}$, corresponding to the $\mathrm{i}^{\text {th }}$ observation as follows:

$\omega_{\mathrm{i}}^{*}=\omega_{\mathrm{i}} / \Sigma \omega_{\mathrm{i}}$. Let $\pi_{0}$ denote the true (population) cell frequencies, given the true (population) value of $\xi$, while $\pi$ denotes the observed cell frequencies from the data, weighted by $\omega_{i}{ }^{*}$. If $\mathrm{N}^{1 / 2}\left(\pi-\pi_{0}\right)$ is to converge in distribution to a mean-zero normal random variable, it must be verified that $\mathrm{N}^{1 / 2}\left(\sum \omega_{\mathrm{i}}^{*} \delta_{\mathrm{i}}-\pi_{0}\right)=$ $\mathrm{N}^{1 / 2} \sum \omega_{\mathrm{i}}{ }^{*}\left(\delta_{\mathrm{i}}-\pi_{0}\right)$. But this follows directly from the fact that the normalized sampling weights, $\omega_{\mathrm{i}}{ }^{*}$, sum to 1, implying $\sum \omega_{\mathrm{i}}^{*} \pi_{0}=\pi_{0}$. The outer product matrix for $\mathrm{N}^{1 / 2} \sum \omega_{\mathrm{i}}^{*}\left(\delta_{\mathrm{i}}-\pi_{0}\right)$ is given by $\left[\mathrm{N}^{1 / 2} \sum \omega_{\mathrm{i}}^{*}\left(\delta_{\mathrm{i}}-\pi_{0}\right)\right]\left[\mathrm{N}^{1 / 2} \sum \omega_{\mathrm{i}}^{*}\left(\delta_{\mathrm{i}}-\pi_{0}\right)\right]^{\prime}$, or $\mathrm{N} \sum \omega_{\mathrm{i}}^{* 2}\left(\delta_{\mathrm{i}}-\pi_{0}\right)\left(\delta_{\mathrm{i}}-\pi_{0}\right)^{\prime}$, the inverse of which is the optimal weighting matrix. Since $\pi_{0}$ is unobserved, a feasible estimator of the optimal weighting matrix substitutes a consistent estimator for $\pi_{0}$, namely $\pi$, yielding $\mathbf{M}=\left[\mathrm{N} \sum \omega_{\mathrm{i}}{ }^{* 2}\left(\delta_{\mathrm{i}}-\pi\right)\left(\delta_{\mathrm{i}}-\pi\right)^{\prime}\right]^{-1}$. Substituting $\omega_{\mathrm{i}}^{*}=\omega_{\mathrm{i}} / \sum \omega_{\mathrm{i}}$ gives the expression for $\mathbf{M}$ given in the text.

${ }^{23}$ The sample size is reduced from 917 to 805 due to missing values in the wage and vacancy duration variables. From the $805 \mathrm{I}$ drop a small fraction (about 4 percent) of recruitment campaigns with extremely long durations, yielding an analysis sample of 770. I do this for two reasons. First, the assumption of the model that the employer cannot switch recruitment strategies during a campaign becomes less tenable for recruitment campaigns of very long duration. Second, the three-point duration distribution I assume has difficulty describing an observed distribution with an extremely long right tail. If the model is estimated on all 805 observations, the qualitative results are similar to those I report here. However, the fit of the model deteriorates due to poor matching of predicted to observed frequencies in the cells corresponding to recruitment campaigns lasting longer than 3 periods.

${ }^{24}$ The method of simulated moments estimator of $\xi_{\text {is }} \xi_{\mathrm{MSM}}=\operatorname{argmin} \mathrm{Q}(\xi)$. The distance function is minimized using the DFP and Newton algorithms in the constrained optimization routine in GAUSS. All stochastic draws are taken using GAUSS's pseudo-random number generators. While a closed form expression is available for $\mathrm{E}\left(\theta_{\mathrm{I}}\right)^{\gamma}$, solving the value function also necessitates computing $\mathrm{E}\left(\theta_{\mathrm{F}(2)}\right)^{\gamma}$, and I do this using Gauss-Legendre quadrature. 
$\mathrm{k}-1$ ), where $\mathrm{Q}$ is the value of the minimized distance function (0.0023), $\mathrm{N}$ is the sample size (770), $\mathrm{n}$ is the number of cells, and $\mathrm{k}$ is the number of estimated parameters. The model cannot be rejected on the basis of a chi-square goodness-of-fit test ( $p$-value $=$ 0.926). The parameter estimates seem plausible and are estimated with high precision. Several points are worth noting. First, for either recruitment strategy the estimated hiring probability when a high wage is posted is substantially higher than when a low wage is posted. Second, when a high wage is posted the hiring probability when informal methods are chosen is substantially higher than when formal methods are chosen, but when a low wage is posted the hiring probability for informal methods only slightly exceeds the one for formal methods. Third, the estimated hiring probability when formal methods are used with a high wage substantially exceeds the one when informal methods are used with a low wage; recall that both probabilities were unconstrained relative to each other in estimation, though they were both constrained to lie in the interval ( $\mathrm{p}_{\mathrm{FL}}$, $\left.\mathrm{p}_{\mathrm{IH}}\right)$. Fourth, the standard deviation of the match quality distributions is small relative to the mean. This arises because the value to the employer of sampling the second order statistic of $\theta_{F}$ (i.e. choosing formal methods) increases rapidly in $\sigma$, so formal methods completely dominate informal methods unless the magnitude of $\sigma$ is modest. Fifth, as discussed earlier, $\beta_{\gamma}$ is slightly below 1 whereas $\alpha_{\gamma}$ is significantly smaller, and this implies a distribution of $\gamma$ that has an asymmetric U-shape, with a lot of probability mass near 0 , and that is nearly monotonically decreasing. This can be seen in Figure 3, in a histogram for $\gamma$ based on 400,000 draws. The figure also displays the graphs of $\mathrm{V}_{1}{ }^{\mathrm{I}}$ and $\mathrm{V}_{1}{ }^{\mathrm{F}}$, given the estimated parameter values, as well as the implied $\gamma^{*}$ thresholds that are also displayed in the first column of Table 5. The graph of the value function, $V$, is the outer envelope of $\mathrm{V}_{1}{ }^{\mathrm{I}}$ and $\mathrm{V}_{1}{ }^{\mathrm{F}}$ in Figure 3.

Since the analysis in this paper is restricted to clerical workers, it is worth asking whether the results would change much if a different occupational group were used instead. To address this question, I aggregate the largest occupational categories (other than clerical) to consider workers in "marketing, sales, and service" occupations who are employed in positions that do not require a college degree. Though there are some differences, the structural estimates obtained from this subsample do not differ dramatically from those in Table 3, suggesting applicability of the analysis of the paper 
beyond the context of clerical workers. Appendix B presents the estimates (in Table B.2) and some further details.

\section{COUNTERFACTUAL SIMULATIONS}

Returning to the analysis of clerical workers, I now consider 3 counterfactual simulations: a wage subsidy, an "information policy" designed to improve match qualities for workers hired via formal methods, and an increase in the degree of labor market heterogeneity in prospective match qualities. I compare each counterfactual to a baseline (or pre-policy) case. To produce the baseline case, given the parameter estimates in Table 3 I generate 5000 draws of $\gamma$, and for each draw I solve the value function by backward induction to find the optimal recruitment strategies and wage offers for that employer-type. I then combine these optimal choices with the random draws representing the stochastic hiring decisions, to compute vacancy duration and starting wages. Since the particular policies in the first two counterfactuals I consider were enacted in 1997 and 1998, whereas the data were collected between 1992 and 1995, it is reasonable to interpret the parameter estimates in Table 3 and the resulting baseline simulations as describing a pre-policy state of the world. For each counterfactual simulation I illustrate the decomposition of the total effect of a change in the economic environment into "pure wage effects" and "recruitment-wage effects".

\section{Simulation 1: Hiring Incentives (WOTC)}

Wage subsidies such as the Work Opportunity Tax Credit (WOTC), introduced in 1997, and the Welfare-to-Work Tax Credit, (WtWTC), introduced in 1998, provide tax incentives to employers to hire low-skilled workers traditionally seen as facing significant barriers to employment. ${ }^{25}$ I model the WOTC as an exogenous one-time

\footnotetext{
${ }^{25}$ The WOTC provides federal income tax credits directly to businesses that hire eligible individuals from various target groups. The maximum credit for new hires working at least 400 hours is $40 \%$ of the first $\$ 6000$ of wages, yielding a maximum credit of $\$ 2400$. The Welfare-to-Work Tax Credit provides federal tax credits directly to businesses that hire workers who have received AFDC benefits for at least eighteen months prior to the hiring date. The other eligibility requirements are the same as those for the WOTC. Employers may claim either the WOTC or the WtWTC for a new hire but not both. The WtWTC is 35\% of the first $\$ 10,000$ of wages in the first year of employment and $50 \%$ of the first $\$ 10,000$ of wages in the second year, yielding a maximum credit of $\$ 8500$ per employee. The new hire must complete a minimum of 400 hours or 180 days of employment for the employer to qualify for the credit.
} 
transfer, received by the employer at the time of hiring, in the amount of nearly five percent of the total earnings of the average new hire in her first two years on the job. ${ }^{26}$ This is the maximum credit an employer could receive under the WOTC. Results from the more generous WtWTC would be qualitatively similar, but larger in magnitude.

Some caveats are worth noting in interpreting this counterfactual as a measure of the actual predicted effects of the WOTC. First, wage subsidies can be expected to have general equilibrium effects that are not captured by this partial equilibrium model that holds constant all worker behavior. Second, the WOTC applies only to targeted worker types, whereas the simulations apply the subsidy to all workers in a homogenous sample of clerical workers. A model that differentiates workers by type would be needed to address the issue of substitution between workers targeted by the policy and those not targeted (DeVaro 2001). Third, the counterfactual assumes that the employer collects the maximum subsidy as soon as the worker is hired, whereas in reality the worker must remain with the employer for two years for the maximum subsidy to be obtained. In reality, the expectation of turnover during the first two years of employment will reduce the expected benefit of the subsidy from the employer's perspective.

The changes in the thresholds in Table 5 between columns 1 and 2 reveal that the WOTC induces a shift towards informal recruitment methods (because $\gamma_{\text {IF1 }}^{*}$ and $\gamma_{\text {IF2 }}^{*}$ increase while $\gamma_{\text {FII }}^{*}$ decreases) and towards wage-offer sequences favoring higher posted wage offers, regardless of recruitment choice (because the $\gamma$-thresholds for wage offers decrease). Intuitively, both responses occur because the wage subsidy increases the attractiveness of a hire in the employer's eyes, and both responses increase the per-period hiring probability. The number of employers actually switching recruitment and wageoffer strategies depends upon the distribution of employer types in the neighborhood of

\footnotetext{
${ }^{26}$ The average hourly starting wage in the analysis sample is $\$ 7.88$ in 1990 dollars. This implies total earnings in the first two years of employment of about $\$ 49,833$ in 2006 dollars, assuming a 40-hour workweek, a 51-week work year, and inflating from 1990 to 2006 dollars using the CPI-U. The maximum credit an employer can receive under the WOTC is $\$ 2400$ during a worker's first two years, which is about 4.8 percent of the worker's total earnings of $\$ 49,833$. Given that the economic model assumes $\mathrm{W}_{\mathrm{L}}=$ 0.7404 and $\mathrm{W}_{\mathrm{H}}=1.1304$, I compute an average starting wage of $(0.587) \mathrm{W}_{\mathrm{L}}+(0.413) \mathrm{W}_{\mathrm{H}}=0.9015$, where the weights in this average are the fractions hired at the high and low wage in the baseline specification (see first column of Table 7). Since this represents earnings over a three-week period, I multiple by 34 (the number of three-week periods in two 51-week work years) to get 30.651. The amount of the subsidy in the counterfactual is about 4.8 percent of this, or 1.48 .
} 
the various $\gamma$-thresholds, as determined by $\alpha_{\gamma}$ and $\beta_{\gamma}$. Panel A of Table 7 displays the transition matrix, expressed as percentages of row sums. For example, 1178 employers chose formal methods with a wage-offer sequence of $\left(\mathrm{W}_{\mathrm{L}}, \mathrm{W}_{\mathrm{L}}, \mathrm{W}_{\mathrm{L}}\right)$ in the baseline. After the policy change, 36.08 percent remained with formal methods but switched to a wage-offer sequence of $\left(\mathrm{W}_{\mathrm{L}}, \mathrm{W}_{\mathrm{L}}, \mathrm{W}_{\mathrm{H}}\right)$, and 63.92 percent switched to informal methods and this new wage-offer sequence.

Comparing columns 1 and 2 of Table 8 reveals that the WOTC increases the percentage of employers using informal methods from 32.9 percent to 49.4 percent, and the fraction of new hires starting at the low wage decreases from 57.3 percent to 52.5 percent. Table 9 disaggregates the information in Table 8 by recruitment choice, revealing that when formal methods are chosen the starting wage distribution shifts clearly to the right, whereas when informal methods are chosen the starting wage distribution shifts slightly to the left. The leftward shift occurs because, as seen in the third quadrant of Panel A of Table 7, of the employers switching from formal to informal methods in response to the policy, more of them choose wage-offer sequences of $\left(\mathrm{W}_{\mathrm{L}}\right.$, $\left.\mathrm{W}_{\mathrm{L}}, \mathrm{W}_{\mathrm{H}}\right)$ than $\left(\mathrm{W}_{\mathrm{H}}, \mathrm{W}_{\mathrm{H}}, \mathrm{W}_{\mathrm{H}}\right)$.

Table 8 reveals that the effect of the WOTC on vacancy duration is nonmonotonic (the fractions hired in period 1 and 3 increase, and the fractions hired in periods 2 and more than 3 decrease). This result can be understood when the information is disaggregated by recruitment choice. Table 9 reveals that when formal methods are chosen, vacancy durations shorten following the WOTC. In contrast, when informal methods are chosen the effect on vacancy duration is non-monotonic (the percentage of campaigns that yields a hire in more than three periods decreases, but so does the percentage of campaigns that yields a hire in the first period). To see why this happens, recall from Panel A of Table 7 that in the baseline, 536/(536+1109), or 32.6 percent, of employers using informal methods offered a high wage in periods 1 and 2, whereas after the policy this number was only 24.6 percent due to an influx of employers switching from formal to informal methods and tending to favor low wage offers in the first two periods. That explains why, for workers hired via informal methods, the percentage hired in period 1 decreases following the policy change. Table 7 also reveals that in the baseline 32.6 percent of employers using informal methods offered a high wage in the 
third period, whereas after the policy change all employers choosing informal methods offer a high wage in the third period. This explains the decrease in the percentage of (informal) recruitment campaigns that extend beyond three periods.

Tables 10 and 11 display the "recruitment-constant" analogs of Tables 8 and 9, meaning I assume the employer is not allowed to switch recruitment strategies following the policy change. Thus, Tables 8 and 9 represent the total effect of the policy changes, Tables 10 and 11 represent "pure wage effects" that operate only through the channel of changes in posted wage offers holding constant recruitment strategies, and the difference between the two sets of results is the "recruitment-wage effect."

Table 11 reveals a clear rightward shift in the starting wage distribution for workers hired via informal methods, in contrast to the slight leftward shift that was seen in the total effects of Table 9, highlighting the important effect of compositional changes on the distribution of starting wages when employers are able to change recruitment strategies in response to the wage subsidy. In the total effects, the dramatic rightward shift in the starting wage distribution for those hired via formal methods implied a clear rightward shift in the overall starting wage distribution, despite the slight leftward shift in starting wages for those hired via informal methods. In the recruitment-constant effects, the rightward shift in the overall starting wage distribution is more muted, despite the fact that starting wages now shift to the right for those hired via informal methods as well as for those hired via formal methods. The reason is that rightward shift for those hired via formal methods is considerably smaller than it was in the total effects of Table 9. Note also that the reason that the recruitment-constant rightward shift in the starting wage distribution is greater for employers using informal methods than for those using formal methods can be found in the estimated hiring probabilities in Table 3, which reveal that the return (in terms of the increase in the hiring probability) to posting a high wage rather than a low one is greater for informal methods than for formal methods. Finally, regarding vacancy duration, the recruitment-constant effects are dampened relative to the total effects in Tables 8 and 9. 
Simulation 2: "Information Policies" (Workforce Investment Act of 1998)

An "information policy" attempts to secure better matches for targeted worker types by enhancing the information available to employers about these workers. An example of such a policy is the Workforce Investment Act of 1998 (WIA98), which targets low-skilled worker groups such as economically disadvantaged adults, youth and dislocated workers. The Act attempts to unify and streamline federally-funded employment and training services by requiring them to be provided through a centralized single system at the local level called the One-Stop Center System. A major function of the one-stop centers is matching job seekers to employers at the local level where the needs of businesses and individuals are best understood. Employers recruiting through the one-stop centers should be privy to more and better information about workers and how well their skills match the specific needs of the firm. ${ }^{27}$ I model this policy as an exogenous increase in $\mathrm{E} \theta_{\mathrm{F}}$, since using a one-stop center corresponds to formal recruitment methods and since the additional intensive information provided by these centers should improve the average match quality. The magnitude of the increase in $\mathrm{E} \theta_{\mathrm{F}}$ that would result from a policy such as WIA98 is unclear, so I arbitrarily consider a small increase of only 1 percent (from 1 to 1.01$){ }^{28}$

The thresholds for $\gamma$ in Table 5 reveal a shift from informal to formal methods and a shift towards higher posted wage offers when formal methods are chosen. Both shifts

\footnotetext{
${ }^{27}$ Localities are given autonomy to plan systems that best suit their local needs, so methods of implementation vary considerably across states and localities, though all centers actively seek to integrate the recruitment activities of local employers with those of the one-stop center. Job seekers who require training services are channeled into programs that directly match the skill needs reported most in demand by local employers. Many one-stop centers encourage employers to use the on-site facilities to recruit, interview, test, and train job candidates. In some centers these functions are carried out via teleconferencing. A common approach is to establish single points-of-contact or liaisons from the one-stop center to a business or business sector, so that one-stop employees can cultivate ongoing relationships with local employers and familiarize themselves with each employer's specific needs. The job matching function of the one-stop centers and the centralization of employment, training and recruitment services facilitates the acquisition of information for both employers and job seekers.

${ }^{28}$ The model is highly sensitive to changes in $\mathrm{E} \theta_{\mathrm{F}}$. Even an increase as small as 1 percent induces a dramatic shift towards formal methods, and an increase of slightly more than 1 percent would cause $\gamma_{\text {FI1 }}^{*}$ and $\gamma_{\mathrm{IF} 2}^{*}$ to coincide and thus disappear altogether, so that informal methods would be chosen only for

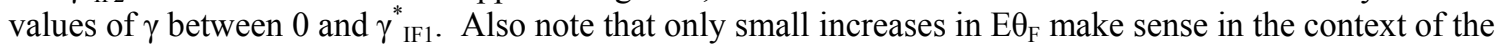
theoretical model, ceteris paribus. For example, the model's assumption that the employer screens more intensively when formal methods are used (i.e. takes the best of two draws from the match quality distribution given that a hire occurs) hinges on $\mathrm{E} \theta_{\mathrm{F}}$ being sufficiently less than $\mathrm{E} \theta_{\mathrm{I}}$. As $\mathrm{E} \theta_{\mathrm{F}}$ increases with $\mathrm{E} \theta_{\mathrm{I}}$ remaining fixed, this assumption regarding screening behavior becomes increasingly questionable.
} 
arise because the policy increases the attractiveness of new hires, given that they are generated via formal methods. Panel B of Table 7 reveals the actual transitions, which are substantial from informal to formal methods though small for increases in wage postings given that formal methods are chosen. Tables 8 and 9 reveal a dramatic shift towards formal recruitment methods, a slightly lower overall starting wage distribution, slightly longer vacancy durations, higher starting wages and shorter vacancy durations for those workers hired via formal methods, and lower starting wages and longer vacancy durations for workers hired via informal methods. Note that the striking decrease in the starting wage distribution for workers hired via informal methods occurs because of the change in composition (in terms of the chosen wage-offer sequences) of the employers who choose informal methods following the policy change, with a much smaller fraction of such employers offering sequences of $\left(\mathrm{W}_{\mathrm{H}}, \mathrm{W}_{\mathrm{H}}, \mathrm{W}_{\mathrm{H}}\right)$ after the change.

Another interesting point is that the distribution of starting wages for all workers shifts slightly to the left, and vacancy durations increase slightly as a result of the policy, and both results might appear counterintuitive absent the insights offered by the structural model. To see the intuition for these results, consider the row of the transition matrix corresponding to IHHH. Only 6.53 percent of these employers remain with this strategy after the policy change, whereas 16.79 percent switch to FLHH and 76.68 percent switch to FHHH. The switchers to FLHH can expect to pay lower starting wages (since some will hire in the first period at the low wage) and endure longer expected vacancy durations (both because of switching to the slower recruitment method and because of switching to a low wage offer in the first period). Similarly, the switchers to FHHH can expect longer vacancy durations as a result of switching to the slower recruitment method. This illustrates again the "recruitment-wage effect", whereby substitution of employers across recruitment strategies in response to an exogenous policy or environmental change has implications for the overall distribution of starting wages (and also vacancy durations). This is a key insight of the model. As seen by comparing Tables 10 and 11 with Tables 8 and 9, virtually the entire change (to 3 significant digits) in the distributions of starting wages and vacancy duration following the policy change is due to shifts in employer recruitment behavior. 
Simulation 3: Increase in Heterogeneity of Prospective Match Qualities

Finally, consider an exogenous increase in $\sigma$, leaving $\mathrm{E}\left(\theta_{\mathrm{I}}\right)$ and $\mathrm{E}\left(\theta_{\mathrm{F}}\right)$ unchanged. This signifies an increase in the degree of heterogeneity of prospective match qualities in the labor market. One interpretation is that this arises from a change in the demographics of potential applicants in the local labor market in which the employer operates that occurs over a long period of time. Another interpretation is that the same employer opens a new establishment in a different regional labor market. Employer recruitment decisions are quite sensitive to changes in $\sigma$, and an increase of about 5.5 percent in this parameter would cause $\gamma_{\text {FI1 }}^{*}$ and $\gamma_{\text {IF2 }}^{*}$ to coincide (and therefore disappear) so that informal methods would only be chosen for values of $\gamma$ between 0 and $\gamma_{\text {IF } 1}^{*}$. I consider a more modest increase of 5 percent in the estimated $\sigma$.

Changes in the thresholds $\gamma_{\mathrm{IF} 1}^{*}, \gamma_{\mathrm{FII}}^{*}$, and $\gamma_{\mathrm{IF} 2}^{*}$ in Table 5 reveal a shift in the direction of formal methods, arising because the benefits to the employer of sampling the second order statistic of $\theta_{\mathrm{F}}$ are increasing in $\sigma$. Furthermore, though the changes are negligible and can rarely be discerned with only 3 significant digits, the remaining $\gamma$ thresholds decrease for formal methods and increase for informal methods. ${ }^{29}$ Thus, an increase in the heterogeneity of potential matches induces some employers to switch from informal to formal methods. Those remaining with informal methods are less likely than before to raise wage offers during the recruitment campaign since (due to concavity in the production function) they are less eager to attract matches of more uncertain quality. Those who remain with formal methods are more likely than before to raise wage offers during the recruitment campaign, since the expected value of the second order statistic of $\theta_{\mathrm{F}}$ is increasing in the variance of $\theta_{\mathrm{F}}$, making the employer more eager to fill the position.

Panel $\mathrm{C}$ of Table 7 quantifies these predicted substitutions. Tables 8 and 9 reveal a dramatic shift towards formal methods, a slight leftward shift in the starting wage distribution, and a slight lengthening of vacancy durations. For workers hired via informal methods there is a clear leftward shift in the starting wage distribution and a

\footnotetext{
${ }^{29}$ For example, in period 3 the equations $E\left[M \theta_{F(2)}\right] \gamma_{F 3}=E\left[M \theta_{F(2)}^{\prime}\right]^{\prime}$ and

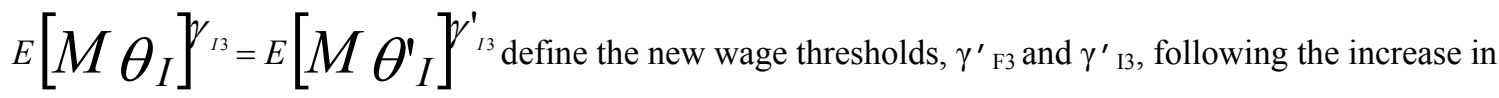


lengthening of vacancy durations, both arising from the change in composition (in terms of their wage-offer sequences) for employers who remain with informal methods after the change. For workers hired via formal methods, the starting wage distribution shifts to the right and vacancy durations decrease. As was the case for WIA98, the somewhat surprising results that the starting wage distribution for all workers shifts to the left and the vacancy duration lengthens after the change are easily explained by the model (in particular the substitutions from IHHH to FLHH and FHHH, as revealed in Panel C of Table 7) and offer another example of the recruitment-wage effect. Comparing Tables 10 and 11 with Tables 8 and 9, we see that the changes in starting wages and vacancy duration following the environmental changes are due to shifts in recruitment behavior.

\section{CONCLUSION}

As the sole means of generating a pool of job applicants, the choice of recruitment strategy is an important problem an employer faces in the process of hiring a new worker. Nevertheless, recruitment behavior is a relatively neglected area of research in labor economics. A complete understanding of the effects of policy and environmental changes affecting hiring processes requires a theoretical framework predicting how employers will respond by adjusting their recruitment strategies. This paper is the first to estimate a dynamic structural model in which recruitment choice is endogenous, exploiting a large cross-sectional establishment-level data set, the Multi-City Study of Urban Inequality. By providing a framework for analyzing how recruitment behavior affects labor market outcomes, I have aimed to partially bridge the gap in our knowledge of an area of obvious interest to economists, policymakers, and employers, and to contribute to a deeper understanding of the effect of information and employer behavior on the job matching process. Furthermore, as seen in Table 8, the structural model successfully predicts two of the basic empirical observations from Section II, namely that secretaries hired via informal methods are hired fasted and at lower starting wages than those hired via formal methods. The observation that secretaries hired via informal methods start at a lower wage than those hired via formal methods might seem

$\sigma$, where $\theta_{\mathrm{F}}{ }^{\prime}$ and $\theta_{\mathrm{I}}{ }^{\prime}$ denote the match-qualities under formal and informal methods, respectively, following the increase in $\sigma$. It is clear from these expressions that $\gamma_{\mathrm{F} 3}{ }^{\prime}<\gamma_{\mathrm{F} 3}$ and $\gamma_{13}{ }^{\prime}>\gamma_{13}$. 
counterintuitive, given the conventional wisdom that informal methods yield better matches on average, but this result is easily understood in light of the structural model.

Although the model presented here assumes only one worker type, an extension to multiple worker types is straightforward as is shown in a similar model in DeVaro (2001). A promising line of future work would be to apply a model with multiple worker types (differentiated by race, ethnicity, or gender) to analyze the effects of affirmative action policies on the hiring process. In such an analysis it would be profitable to model job seekers' selection of job search methods, since these methods sometimes vary considerably by personal characteristics such as race, age, gender, and educational attainment. Although the issue of selection on the part of job seekers is not treated in this paper, it implicitly underlies the employer's recognition that certain recruitment activities are more likely than others to generate workers of a particular match quality. Thus, if the employer seeks a certain worker-type the recruitment choice is a powerful mechanism influencing the probability of a successful hire. 


\section{REFERENCES}

Albrecht, J.W., Gautier P.A., and S.B. Vroman (2006). "Equilibrium Directed Search with Multiple Applications." Review of Economic Studies, forthcoming.

DeVaro, Jed (2005). "Employer Recruitment Strategies and the Labor Market Outcomes of New Hires." Economic Inquiry. Vol. 43, pp. 263-282.

DeVaro, Jed (2001). "The Effects of Employer Recruitment Strategies on Job Placements and Match Quality." Doctoral dissertation, Stanford University. Also available as Stanford Institute for Economic Policy Research (SIEPR) discussion paper no. 01-06.

Granovetter, Mark S (1995). Getting $a$ Job. $2^{\text {nd }}$ ed. Cambridge, MA: Harvard Press.

Holzer, Harry (1996). What Employers Want: Job Prospects for Less-Educated Workers. New York: Russell Sage Foundation.

Montgomery, James D. "Social Networks and Labor-Market Outcomes: Toward an Economic Analysis." American Economic Review, Vol. 81 No. 5 (December, 1991).

Mortensen, Dale T., and Vishwanath, T. (1994). "Information Sources and Equilibrium Wage Outcomes: It is Who You Know!," Labour Economics 1, pp. $187-201$.

Rees, Albert. "Information Networks in Labor Markets." American Economic Review 56: 1966.

Rees, Albert and George P. Schultz. 1970. Workers and Wages in an Urban Labor Market. Chicago: University of Chicago Press.

Stigler, George J. "Information in the Labor Market." Journal of Political Economy. October 1962. 
Table 1: Descriptive Statistics by Recruitment Method

\begin{tabular}{|l|l|l|l|}
\hline & Informal & Formal & Difference \\
\hline Vacancy Duration (Weeks) & 2.630 & 3.637 & -1.006 \\
& $(0.190)$ & $(0.280)$ & $(0.338)$ \\
\hline Real Hourly Starting Wage (\$1990) & 7.546 & 8.097 & -0.552 \\
& $(0.145)$ & $(0.132)$ & $(0.196)$ \\
\hline Number of Applicants & 25.737 & 176.135 & -150.398 \\
& $(6.028)$ & $(110.034)$ & $(110.199)$ \\
\hline Number of Interviews & 7.827 & 11.345 & -3.518 \\
& $(1.548)$ & $(0.952)$ & $(1.817)$ \\
\hline Total sample size $=N_{I}+N_{F}=917$ & $N_{I}=291$ & $N_{F}=626$ & \\
\hline
\end{tabular}

Notes: Cell entries are means, with standard errors in parentheses. Sample is 917 clerical workers. First column is the subsample generated via informal methods, and second column is the subsample generated by some other means (e.g. newspaper advertisements). All statistics are computed using sampling weights.

Table 2: Relationship Between Changes in Recruitment and Screening Methods Dependent Variable $=0$ if informal recruitment methods are used less often now than 5-10 years ago, $=1$ if no change, $=2$ if used more now than 5-10 years ago

\begin{tabular}{|c|c|c|c|c|c|c|}
\hline & (1) & (2) & (3) & (4) & (5) & (6) \\
\hline Interview Less? & $\begin{array}{l}0.936 \\
(0.522)\end{array}$ & $\bullet$ & $\bullet$ & $\bullet$ & $\bullet$ & $\begin{array}{l}0.931 \\
(0.498)\end{array}$ \\
\hline Test Less? & $\bullet$ & $\begin{array}{l}0.345 \\
(0.237)\end{array}$ & $\bullet$ & $\bullet$ & $\bullet$ & $\begin{array}{l}0.238 \\
(0.243)\end{array}$ \\
\hline Check References Less? & - & - & $\begin{array}{l}0.116 \\
(0.320)\end{array}$ & - & - & $\begin{array}{l}-0.179 \\
(0.358)\end{array}$ \\
\hline Check Educational Record Less? & - & - & - & $\begin{array}{l}0.554 \\
(0.175)\end{array}$ & - & $\begin{array}{l}0.523 \\
(0.200)\end{array}$ \\
\hline Check Criminal Record Less? & - & - & - & - & $\begin{array}{l}0.235 \\
(0.142)\end{array}$ & $\begin{array}{l}0.055 \\
(0.160)\end{array}$ \\
\hline
\end{tabular}

Notes: Results are from 6 ordered probit models. Sample is 917 clerical workers. Dependent variable is 3-valued indicator of whether recruitment methods (for the position in which the most recent worker started) are used less often, as often, or more often as of the survey date compared with 5 - 10 years ago. Independent variables are binary indicators for whether particular screening methods are used less often as of the survey date compared with $5-10$ years ago. All models use sampling weights.

\section{Table 3: Structural Parameter Estimates ${ }^{1}$}

\begin{tabular}{l|c|}
\hline Parameters & Asymptotic Standard Errors \\
\hline $\mathrm{M}=20.144$ & 4.752 \\
$\alpha_{\gamma}=0.651$ & 0.005 \\
$\beta_{\gamma}=0.961$ & 0.011 \\
$\mu=1.131$ & 0.036 \\
$\sigma=0.445$ & 0.005 \\
$\mathrm{p}_{\mathrm{IH}}=0.959$ & 0.024 \\
$\mathrm{p}_{\mathrm{IL}}=0.673$ & 0.031 \\
$\mathrm{p}_{\mathrm{FH}}=0.809$ & 0.021 \\
$\mathrm{p}_{\mathrm{FL}}=0.647$ & 0.030 \\
\hline
\end{tabular}

${ }^{1}$ I imposed these restrictions when estimating the model:

$\mathrm{W}_{\mathrm{H}}=1.1304 ; \mathrm{W}_{\mathrm{L}}=0.7404 ; \mathrm{p}_{\mathrm{IH}}>\mathrm{p}_{\mathrm{IL}} ; \mathrm{p}_{\mathrm{FH}}>\mathrm{p}_{\mathrm{FL}} ; \mathrm{p}_{\mathrm{IH}}>\mathrm{p}_{\mathrm{FH}} ;$ $\mathrm{p}_{\mathrm{IL}}>\mathrm{p}_{\mathrm{FL}} ; \mathrm{E}\left(\theta_{\mathrm{F}}\right)=1 ; \mathrm{E}\left(\theta_{\mathrm{I}}\right)=\mu>1 ; \operatorname{Var}\left(\theta_{\mathrm{I}}\right)=\operatorname{Var}\left(\theta_{\mathrm{F}}\right)=\sigma ;$ and $\beta=1$, where $\beta$ is the one-period discount factor. 
Table 4: Goodness of Fit

\begin{tabular}{|c|c|c|c|c|c|}
\hline Cell & Recruitment Strategy & Hiring Period & Starting Wage & \% Observed & $\%$ Predicted \\
\hline 1 & Informal Methods & Period 1 & High & 10.43 & 9.90 \\
\hline 2 & Informal Methods & Period 2 & High & 3.04 & 0.70 \\
\hline 3 & Informal Methods & Period 3 & High & 0.87 & 0.00 \\
\hline 4 & Informal Methods & Period 1 & Low & 15.45 & 15.60 \\
\hline 5 & Informal Methods & Period 2 & Low & 2.71 & 3.70 \\
\hline 6 & Informal Methods & Period 3 & Low & 0.87 & 1.10 \\
\hline 7 & Informal Methods & Not Hired & -- & 0.03 & 0.70 \\
\hline 8 & Formal Methods & Period 1 & High & 20.66 & 19.70 \\
\hline 9 & Formal Methods & Period 2 & High & 8.61 & 8.30 \\
\hline 10 & Formal Methods & Period 3 & High & 3.16 & 1.80 \\
\hline 11 & Formal Methods & Period 1 & Low & 28.23 & 27.20 \\
\hline 12 & Formal Methods & Period 2 & Low & 4.54 & 7.80 \\
\hline 13 & Formal Methods & Period 3 & Low & 1.28 & 2.00 \\
\hline 14 & Formal Methods & Not Hired & -- & 0.13 & 1.50 \\
\hline
\end{tabular}

Note: The model cannot be rejected on the basis of a chi-square test of goodness of fit. The test statistic is $0.5 \times \mathrm{Q} \times \mathrm{N}=0.889$, where $\mathrm{Q}=0.0023$ is the value of the minimized distance function, and $\mathrm{N}=770$ is the sample size. Test statistic is distributed $\chi^{2}(\mathrm{n}-\mathrm{k}-1)$ where $\mathrm{n}$ is the number of cells (14) and $\mathrm{k}$ is the number of estimated parameters (9). $\mathrm{p}$-value $=0.926$.

Table 5: Estimated Thresholds for $\gamma$

\begin{tabular}{|l|c|c|c|c|}
\hline & Baseline & WOTC & WIA98 & Heterogeneity \\
\hline$\gamma_{\text {IF1 }}^{*}$ & 0.100 & 0.223 & 0.087 & 0.088 \\
\hline$\gamma_{\mathrm{I} 3}$ & 0.233 & 0.000 & 0.233 & 0.233 \\
\hline$\gamma_{\mathrm{F} 3}$ & 0.311 & 0.058 & 0.310 & 0.311 \\
\hline$\gamma_{\mathrm{I} 2}$ & 0.345 & 0.338 & 0.345 & 0.345 \\
\hline$\gamma_{\mathrm{F} 2}$ & 0.415 & 0.395 & 0.414 & 0.414 \\
\hline$\gamma_{\mathrm{II}}$ & 0.430 & 0.429 & 0.430 & 0.430 \\
\hline$\gamma_{\mathrm{FI} 1}^{*}$ & 0.478 & 0.471 & 0.498 & 0.498 \\
\hline$\gamma_{\mathrm{F} 1}$ & 0.501 & 0.498 & 0.500 & 0.500 \\
\hline$\gamma^{*}{ }_{\mathrm{IF} 2}$ & 0.604 & 0.615 & 0.506 & 0.509 \\
\hline
\end{tabular}

Note: See Propositions 1 and 2 for definitions of these thresholds. The baseline thresholds use the parameter estimates in Table 3, whereas those in the subsequent 3 columns reflect an exogenous change to one of the parameters. 
Table 6: Summary Statistics for Marginal Effects from Monte-Carlo Experiments

\begin{tabular}{|c|c|c|c|c|c|}
\hline & $\%$ Informal & $\% \mathrm{~W}_{\mathrm{H}}$ & $\%$ Hired in 1 & $\%$ Hired in 2 & $\%$ Hired in 3 \\
\hline \multirow{4}{*}{$\alpha_{1}$} & -0.574 & 0.573 & 0.180 & -0.143 & -0.002 \\
\hline & {$[-0.575]$} & [0.558] & [0.190] & {$[-0.165]$} & {$[0.020]$} \\
\hline & $(0.101)$ & $(0.219)$ & $(0.423)$ & $(0.426)$ & $(0.238)$ \\
\hline & -0.600 & 0.558 & 0.730 & -0.700 & 0.100 \\
\hline \multirow{4}{*}{$\beta_{1}$} & 0.352 & -0.523 & -0.158 & 0.121 & 0.053 \\
\hline & {$[0.360]$} & {$[-0.516]$} & {$[-0.130]$} & {$[0.125]$} & {$[0.050]$} \\
\hline & $(0.091)$ & $(0.221)$ & $(0.439)$ & $(0.435)$ & $(0.199)$ \\
\hline & 0.670 & -0.346 & -0.140 & 0.130 & 0.120 \\
\hline \multirow{4}{*}{ M } & 0.583 & 0.291 & 0.131 & -0.085 & -0.030 \\
\hline & {$[0.580]$} & {$[0.288]$} & [0.130] & {$[-0.090]$} & {$[-0.030]$} \\
\hline & $(0.071)$ & $(0.058)$ & $(0.043)$ & $(0.039)$ & $(0.023)$ \\
\hline & 0.690 & 0.325 & 0.100 & -0.050 & -0.020 \\
\hline \multirow{4}{*}{$\sigma$} & -4.790 & -0.395 & -0.717 & 0.520 & 0.149 \\
\hline & {$[-4.780]$} & {$[-0.383]$} & {$[-0.720]$} & {$[0.520]$} & {$[0.145]$} \\
\hline & $(0.102)$ & $(0.067)$ & $(0.100)$ & $(0.085)$ & $(0.063)$ \\
\hline & -4.740 & -0.339 & -0.670 & 0.470 & 0.130 \\
\hline \multirow{4}{*}{$\mu$} & 32.394 & 2.169 & 4.628 & -3.412 & -0.912 \\
\hline & [32.425] & {$[2.176]$} & [4.620] & {$[-3.410]$} & {$[-0.910]$} \\
\hline & $(0.452)$ & $(0.117)$ & $(0.252)$ & $(0.242)$ & $(0.109)$ \\
\hline & 32.290 & 2.168 & 4.380 & -3.180 & -0.940 \\
\hline \multirow{4}{*}{$\mathrm{p}_{\mathrm{IH}}$} & 10.425 & 1.201 & 2.193 & -1.724 & -0.381 \\
\hline & [10.430] & [1.198] & [2.190] & {$[-1.720]$} & {$[-0.390]$} \\
\hline & $(0.092)$ & $(0.085)$ & $(0.129)$ & $(0.111)$ & $(0.062)$ \\
\hline & 10.360 & 1.331 & 2.060 & -1.620 & -0.320 \\
\hline \multirow{4}{*}{$\mathrm{p}_{\mathrm{FL}}$} & -12.338 & -2.312 & -0.227 & 0.226 & 0.017 \\
\hline & {$[-12.320]$} & {$[-2.274]$} & {$[-0.250]$} & {$[0.205]$} & {$[0.020]$} \\
\hline & $(0.223)$ & $(0.160)$ & $(0.200)$ & $(0.179)$ & $(0.133)$ \\
\hline & -12.750 & -2.439 & -0.120 & 0.030 & 0.130 \\
\hline \multirow{4}{*}{$\mathrm{p}_{\mathrm{FH}}$} & -9.837 & 0.298 & -0.859 & 0.861 & 0.052 \\
\hline & {$[-9.830]$} & {$[0.295]$} & {$[-0.850]$} & {$[0.850]$} & {$[0.040]$} \\
\hline & $(0.415)$ & $(0.091)$ & $(0.164)$ & $(0.154)$ & $(0.066)$ \\
\hline & -10.450 & 0.230 & -1.040 & 0.910 & 0.190 \\
\hline \multirow{4}{*}{$\mathrm{p}_{\mathrm{IL}}$} & 11.779 & -0.128 & 0.776 & -0.172 & -0.317 \\
\hline & [11.760] & {$[-0.124]$} & {$[0.760]$} & {$[-0.170]$} & {$[-0.320]$} \\
\hline & $(0.142)$ & $(0.043)$ & $(0.250)$ & $(0.204)$ & $(0.125)$ \\
\hline & 12.120 & -0.088 & 0.820 & -0.250 & -0.370 \\
\hline
\end{tabular}

Notes: Using the parameter estimates in Table 3,100 data sets of size 5,000 were generated and the parameters were estimated. For each of the resulting 100 parameter vectors, parameter $\mathrm{j}$ was increased by $2 \%$ and a data set of size 10,000 was generated to produce the fraction using informal recruiting methods, the fraction starting at the high wage, the fraction hired in period 1 , the fraction hired in period 2 , and the fraction hired in period 3. From these were subtracted the corresponding fractions when parameter $j$ was not increased. Cell ij in the table contains 4 numbers. The first is the mean (across the 100 Monte Carlo replications) marginal effect of parameter i on moment $\mathrm{j}$. The second, in brackets, is the median. The third, in parentheses, is the standard deviation. The fourth, in italics, is the marginal effect computed analogously but using the estimates in Table 3 (based on the real data rather than the Monte Carlo data). Sample sizes of 10,000 were used in all cases. All cell entries are multiplied by 100 for easier reading. 
Table 7: Transition Percentages Following a Policy Change

Panel A: Work Opportunity Tax Credit (WOTC)

\begin{tabular}{|l|l|l|l|l|l|l|l|l|l|}
\hline & ILLL & ILLH & ILHH & IHHH & FLLL & FLLH & FLHH & FHHH & Total \\
\hline ILLL & 0 & 100 & 0 & 0 & 0 & 0 & 0 & 0 & 1109 \\
\hline ILLH & 0 & 0 & 0 & 0 & 0 & 0 & 0 & 0 & 0 \\
\hline ILHH & 0 & 0 & 0 & 0 & 0 & 0 & 0 & 0 & 0 \\
\hline IHHH & 0 & 0 & 0 & 100 & 0 & 0 & 0 & 0 & 536 \\
\hline FLLL & 0 & 63.92 & 0 & 0 & 0 & 36.08 & 0 & 0 & 1178 \\
\hline FLLH & 0 & 0 & 0 & 0 & 0 & 82.88 & 17.12 & 0 & 473 \\
\hline FLHH & 0 & 0 & 0 & 10.37 & 0 & 0 & 89.63 & 0 & 270 \\
\hline FHHH & 0 & 0 & 0 & 2.93 & 0 & 0 & 0 & 97.07 & 1434 \\
\hline
\end{tabular}

Panel B: Workforce Investment Act of 1998 (WIA98)

\begin{tabular}{|l|l|l|l|l|l|l|l|l|l|}
\hline & ILLL & ILLH & ILHH & IHHH & FLLL & FLLH & FLHH & FHHH & Total \\
\hline ILLL & 90.26 & 0 & 0 & 0 & 9.74 & 0 & 0 & 0 & 1109 \\
\hline ILLH & 0 & 0 & 0 & 0 & 0 & 0 & 0 & 0 & 0 \\
\hline ILHH & 0 & 0 & 0 & 0 & 0 & 0 & 0 & 0 & 0 \\
\hline IHHH & 0 & 0 & 0 & 6.53 & 0 & 0 & 16.79 & 76.68 & 536 \\
\hline FLLL & 0 & 0 & 0 & 0 & 99.49 & 0.51 & 0 & 0 & 1178 \\
\hline FLLH & 0 & 0 & 0 & 0 & 0 & 98.94 & 1.06 & 0 & 473 \\
\hline FLHH & 0 & 0 & 0 & 0 & 0 & 0 & 100 & 0 & 270 \\
\hline FHHH & 0 & 0 & 0 & 0 & 0 & 0 & 0 & 100 & 1434 \\
\hline
\end{tabular}

Panel C: Increase in heterogeneity of potential match qualities ( $\sigma$-increase)

\begin{tabular}{|l|l|l|l|l|l|l|l|l|l|}
\hline & ILLL & ILLH & ILHH & IHHH & FLLL & FLLH & FLHH & FHHH & Total \\
\hline ILLL & 90.62 & 0 & 0 & 0 & 9.38 & 0 & 0 & 0 & 1109 \\
\hline ILLH & 0 & 0 & 0 & 0 & 0 & 0 & 0 & 0 & 0 \\
\hline ILHH & 0 & 0 & 0 & 0 & 0 & 0 & 0 & 0 & 0 \\
\hline IHHH & 0 & 0 & 0 & 8.58 & 0 & 0 & 16.79 & 74.63 & 536 \\
\hline FLLL & 0 & 0 & 0 & 0 & 99.75 & 0.25 & 0 & 0 & 1178 \\
\hline FLLH & 0 & 0 & 0 & 0 & 0 & 99.37 & 0.63 & 0 & 473 \\
\hline FLHH & 0 & 0 & 0 & 0 & 0 & 0 & 100 & 0 & 270 \\
\hline FHHH & 0 & 0 & 0 & 0 & 0 & 0 & 0 & 100 & 1434 \\
\hline
\end{tabular}

Notes: In each panel the row titles correspond to baseline recruitment strategies, and the column titles refer to post-policy recruitment strategies. Each strategy is described by 4 letters. The first (I or F) denotes the recruitment strategy. The second, third, and fourth, denote the wage-offers in Periods 1, 2, and 3. Thus, a strategy of FLLH uses formal recruitment methods, low wage offers in Periods 1 and 2 and a high wage offer in Period 3. Row percentages sum to 100. The last column gives the number of simulated recruitment campaigns (out of 5000) for which the row-title strategy was chosen in the baseline case. Thus, the counts in the last column sum to 5000, the total number of simulated recruitment campaigns. 
Table 8: Distributions of Outcomes Based on Simulated Data

\begin{tabular}{l|cccc}
\hline & Baseline & WOTC & WIA98 & $\sigma$-Increase \\
\hline Recruitment & & & & \\
$\quad$ \%Informal & $32.9 \%$ & $49.4 \%$ & $20.7 \%$ & $21.0 \%$ \\
$\quad$ \%Formal & $67.1 \%$ & $50.6 \%$ & $79.3 \%$ & $79.0 \%$ \\
Starting Wage & & & & \\
Low & $57.3 \%$ & $52.5 \%$ & $58.5 \%$ & $58.5 \%$ \\
High & $42.8 \%$ & $47.5 \%$ & $41.5 \%$ & $41.5 \%$ \\
Vacancy Duration & & & & \\
Hired in Period 1 & $74.1 \%$ & $74.8 \%$ & $72.4 \%$ & $72.4 \%$ \\
Hired in Period 2 & $18.1 \%$ & $17.8 \%$ & $19.5 \%$ & $19.4 \%$ \\
Hired in Period 3 & $5.6 \%$ & $6.6 \%$ & $5.9 \%$ & $5.9 \%$ \\
Hired after Period 3 & $2.2 \%$ & $0.7 \%$ & $2.2 \%$ & $2.2 \%$ \\
\hline
\end{tabular}

Notes: Based on 5000 simulated recruitment campaigns.

Table 9: Distributions of Outcomes by Recruitment Strategy

\begin{tabular}{|c|c|c|c|c|}
\hline & Baseline & WOTC & $\overline{W I A 98}$ & $\sigma$-Increase \\
\hline \multicolumn{5}{|l|}{ INFORMAL METHODS } \\
\hline \multicolumn{5}{|l|}{ Starting Wage } \\
\hline Low Wage & $66.5 \%$ & $67.8 \%$ & $96.5 \%$ & $95.4 \%$ \\
\hline High Wage & $33.5 \%$ & $32.2 \%$ & $3.5 \%$ & $4.6 \%$ \\
\hline \multicolumn{5}{|l|}{ Vacancy Duration } \\
\hline Hired in Period 1 & $77.6 \%$ & $75.5 \%$ & $70.0 \%$ & $70.0 \%$ \\
\hline Hired in Period 2 & $15.0 \%$ & $16.5 \%$ & $19.0 \%$ & $19.0 \%$ \\
\hline Hired in Period 3 & $4.7 \%$ & $7.5 \%$ & $7.0 \%$ & $7.0 \%$ \\
\hline Hired after Period 3 & $2.7 \%$ & $0.5 \%$ & $4.0 \%$ & $4.0 \%$ \\
\hline \multicolumn{5}{|l|}{ FORMAL METHODS } \\
\hline \multicolumn{5}{|l|}{ Starting Wage } \\
\hline Low Wage & $52.8 \%$ & $37.5 \%$ & $48.8 \%$ & $48.9 \%$ \\
\hline High Wage & $47.3 \%$ & $62.5 \%$ & $51.2 \%$ & $51.1 \%$ \\
\hline \multicolumn{5}{|l|}{ Vacancy Duration } \\
\hline Hired in Period 1 & $72.4 \%$ & $74.2 \%$ & $73.1 \%$ & $73.1 \%$ \\
\hline Hired in Period 2 & $19.6 \%$ & $19.0 \%$ & $19.6 \%$ & $19.6 \%$ \\
\hline Hired in Period 3 & $6.1 \%$ & $5.8 \%$ & $5.6 \%$ & $5.7 \%$ \\
\hline Hired after Period 3 & $1.9 \%$ & $1.0 \%$ & $1.7 \%$ & $1.7 \%$ \\
\hline
\end{tabular}

Notes: Based on 5000 simulated recruitment campaigns. 
Table 10: "Recruitment-Constant" Distributions of Simulated Outcomes

\begin{tabular}{l|cccc}
\hline & Baseline & WOTC & WIA98 & $\sigma$-Increase \\
\hline Recruitment & & & & \\
$\quad$ \%Informal & $32.9 \%$ & $32.9 \%$ & $32.9 \%$ & $32.9 \%$ \\
$\quad$ \%Formal & $67.1 \%$ & $67.1 \%$ & $67.1 \%$ & $67.1 \%$ \\
Starting Wage & & & & \\
Low & $57.3 \%$ & $52.6 \%$ & $57.3 \%$ & $57.3 \%$ \\
High & $42.8 \%$ & $47.4 \%$ & $42.8 \%$ & $42.8 \%$ \\
Vacancy Duration & & & & \\
Hired in Period 1 & $74.1 \%$ & $74.1 \%$ & $74.1 \%$ & $74.1 \%$ \\
Hired in Period 2 & $18.1 \%$ & $18.2 \%$ & $18.1 \%$ & $18.1 \%$ \\
Hired in Period 3 & $5.6 \%$ & $6.8 \%$ & $5.6 \%$ & $5.6 \%$ \\
Hired after Period 3 & $2.2 \%$ & $1.0 \%$ & $2.2 \%$ & $2.2 \%$ \\
\hline
\end{tabular}

Notes: Based on 5000 simulated recruitment campaigns. The second, third, and fourth columns reflect the distributions of starting wages and vacancy duration that would arise if employers remained with their original recruitment choice after the policy change.

Table 11: "Recruitment-Constant" Distributions by Recruitment Choice

\begin{tabular}{|c|c|c|c|c|}
\hline & Baseline & WOTC & WIA98 & $\sigma$-Increase \\
\hline \multicolumn{5}{|l|}{ INFORMAL METHODS } \\
\hline \multicolumn{5}{|l|}{ Starting Wage } \\
\hline Low Wage & $66.5 \%$ & $60.2 \%$ & $66.5 \%$ & $66.5 \%$ \\
\hline High Wage & $33.5 \%$ & $39.8 \%$ & $33.5 \%$ & $33.5 \%$ \\
\hline \multicolumn{5}{|l|}{ Vacancy Duration } \\
\hline Hired in Period 1 & $77.6 \%$ & $77.6 \%$ & $77.6 \%$ & $77.6 \%$ \\
\hline Hired in Period 2 & $15.0 \%$ & $15.0 \%$ & $15.0 \%$ & $15.0 \%$ \\
\hline Hired in Period 3 & $4.7 \%$ & $7.1 \%$ & $4.7 \%$ & $4.7 \%$ \\
\hline Hired after Period 3 & $2.7 \%$ & $0.4 \%$ & $2.7 \%$ & $2.7 \%$ \\
\hline \multicolumn{5}{|l|}{ FORMAL METHODS } \\
\hline \multicolumn{5}{|l|}{ Starting Wage } \\
\hline Low Wage & $52.8 \%$ & $48.9 \%$ & $52.8 \%$ & $52.8 \%$ \\
\hline High Wage & $47.3 \%$ & $51.1 \%$ & $47.3 \%$ & $47.3 \%$ \\
\hline \multicolumn{5}{|l|}{ Vacancy Duration } \\
\hline Hired in Period 1 & $72.4 \%$ & $72.4 \%$ & $72.4 \%$ & $72.4 \%$ \\
\hline Hired in Period 2 & $19.6 \%$ & $19.7 \%$ & $19.6 \%$ & $19.6 \%$ \\
\hline Hired in Period 3 & $6.1 \%$ & $6.7 \%$ & $6.1 \%$ & $6.1 \%$ \\
\hline Hired after Period 3 & $1.9 \%$ & $1.2 \%$ & $1.9 \%$ & $1.9 \%$ \\
\hline
\end{tabular}

Notes: Based on 5000 simulated recruitment campaigns. The second, third, and fourth columns reflect the distributions of starting wages and vacancy duration that would arise if employers remained with their original recruitment choice after the policy change. 


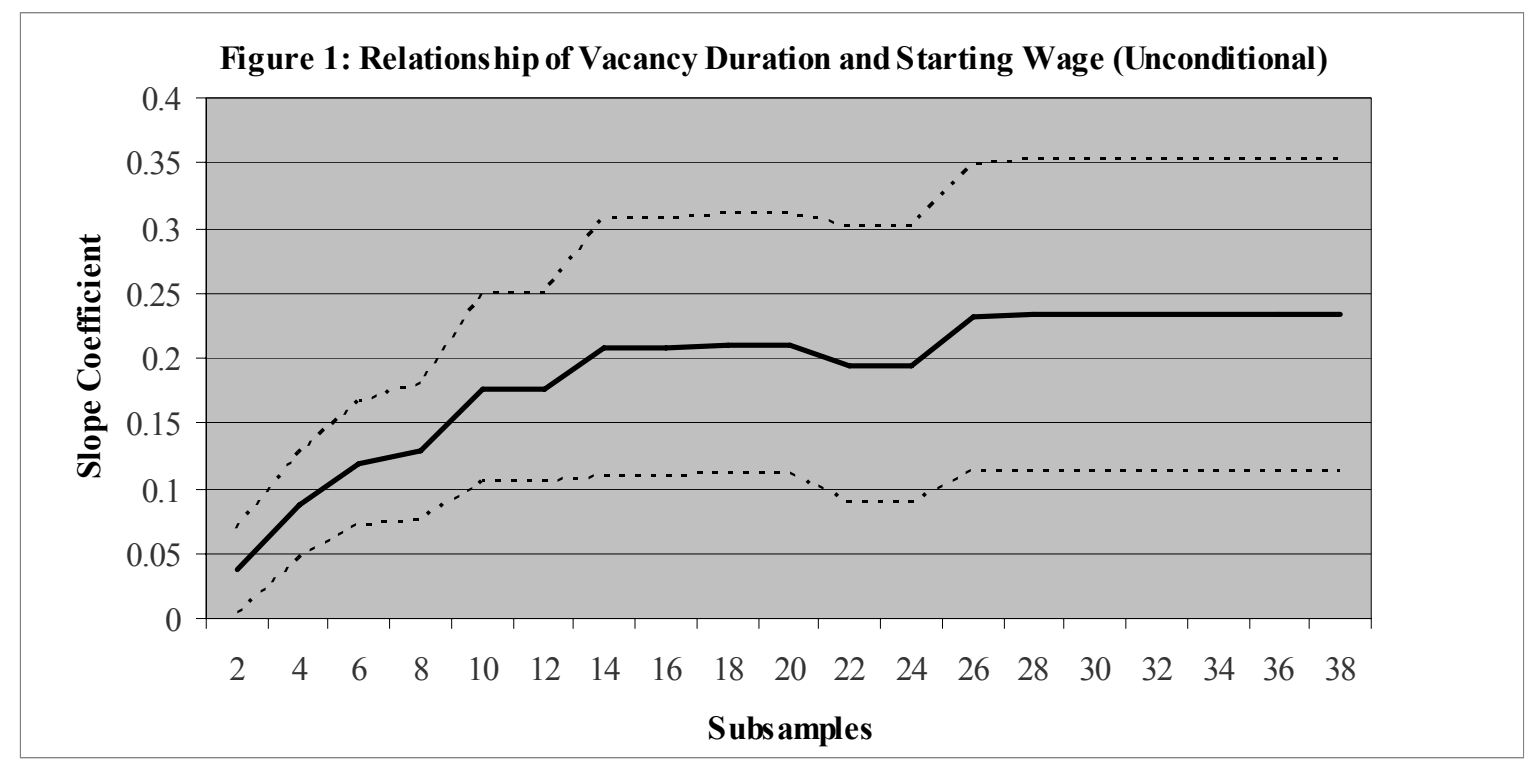

Note: Slope coefficient of regression of vacancy duration (measured in weeks) on a constant and the starting wage. Horizontal axis gives the subsample over which the regression was run. For example, "4" indicates that the sample includes only those employers who filled the position in less than four weeks. $95 \%$ confidence intervals are also plotted for each coefficient.

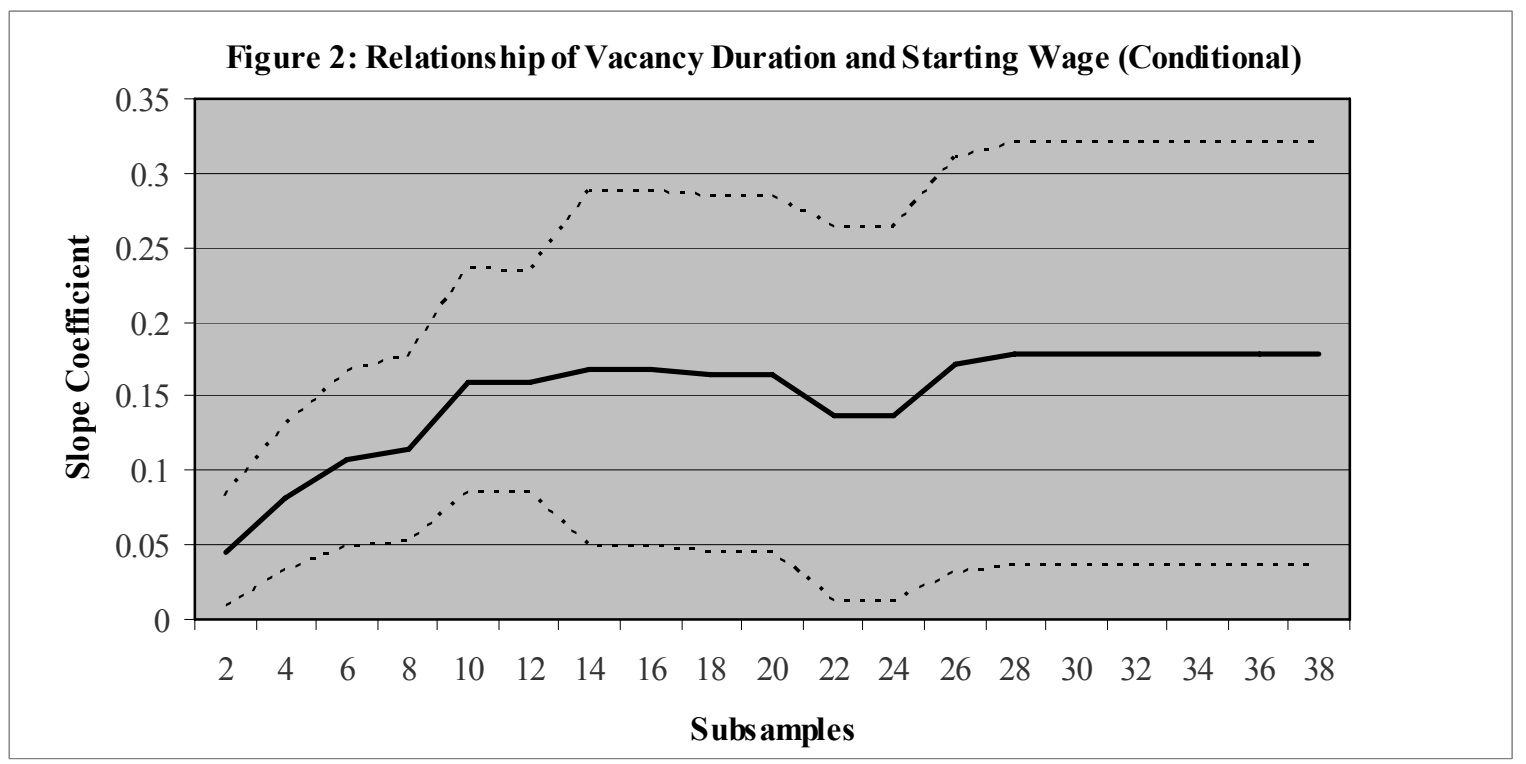

Note: Slope coefficient of regression of vacancy duration (measured in weeks) on a constant, the starting wage, establishment size, number of sites of operation, whether the establishment is a franchise, the fraction of union workers, industry controls, occupation controls, and whether the position requires a college degree. Horizontal axis gives the subsample over which the regression was run. For example, "4" indicates that the sample includes only those employers who filled the position in less than four weeks. $95 \%$ confidence intervals are also plotted for each coefficient. 
Figure 3: Histogram of $\gamma$ Based on 400,000 Draws Using Parameter Estimates in Table 3

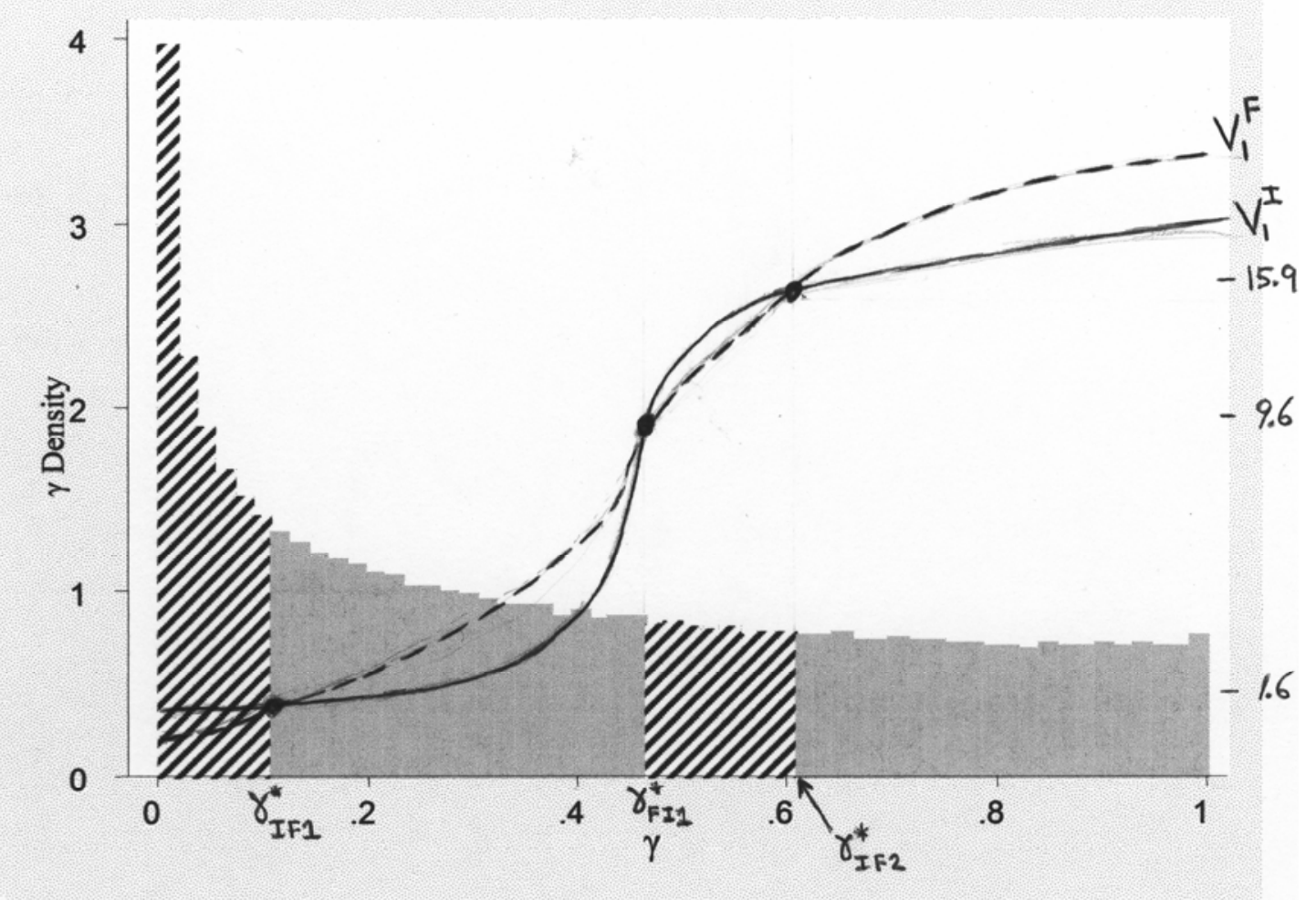

Notes: Dark lined (light solid) shaded regions for $\gamma$ correspond to a choice of informal (formal) recruitment methods. Solid line depicts $\mathrm{V}_{1}{ }^{\mathrm{I}}$ and dotted line depicts $\mathrm{V}_{1}^{\mathrm{F}}$, both evaluated at the estimated parameters (Table 3 ). Right-vertical axis is for the value function and is adjusted so the intersections of $\mathrm{V}_{1}{ }^{\mathrm{I}}$ and $\mathrm{V}_{1}{ }^{\mathrm{F}}$ can be seen easily. Actual $\gamma^{*}$ cutoffs are displayed in Table 5. 


\section{APPENDIX A}

Proof of Proposition 1: Suppose that informal methods are chosen, since the argument for formal methods differs only in notation. In period 3 the employer chooses $\mathrm{W}_{\mathrm{H}}$ if and only if $\left(\mathrm{p}_{\mathrm{IH}} / \mathrm{p}_{\mathrm{IL}}\right)\left[\mathrm{E}\left(\mathrm{M} \theta_{\mathrm{I}}\right)^{\gamma}-\mathrm{W}_{\mathrm{H}}\right]>\left[\mathrm{E}\left(\mathrm{M} \theta_{\mathrm{I}}\right)^{\gamma}-\mathrm{W}_{\mathrm{L}}\right]$. Note that both the left-hand and righthand sides of this inequality are functions of $\gamma$, defined on $[0,1]$, that are monotonically increasing and convex in $\gamma$, crossing at most once, with the function on the left-hand side increasing more rapidly than the function on the right-hand side. $\gamma_{\mathrm{I} 3}=0$ if and only if the inequality holds $\forall \gamma$, and $\gamma_{13}=1$ if and only if there is no value of $\gamma$ for which the inequality holds. Otherwise, $\gamma_{13}$ is in $(0,1)$ and is the value of $\gamma$ that solves the equation $\left(\mathrm{p}_{\mathrm{IH}} / \mathrm{p}_{\mathrm{IL}}\right)\left[\mathrm{E}\left(\mathrm{M} \theta_{\mathrm{I}}\right)^{\gamma}-\mathrm{W}_{\mathrm{H}}\right]=\left[\mathrm{E}\left(\mathrm{M} \theta_{\mathrm{I}}\right)^{\gamma}-\mathrm{W}_{\mathrm{L}}\right]$. Similar arguments define $\gamma_{\mathrm{I} 2}$ and $\gamma_{\mathrm{I} 1}$, though the relevant inequalities describing when $\mathrm{W}_{\mathrm{H}}$ is chosen in periods 2 and 1 are $\left(\mathrm{p}_{\mathrm{IH}} / \mathrm{p}_{\mathrm{IL}}\right)\left[\mathrm{E}\left(\mathrm{M} \theta_{\mathrm{I}}\right)^{\gamma}-\mathrm{W}_{\mathrm{H}}-\beta \mathrm{V}_{3}^{\mathrm{I}} /(1+\beta)\right]>\mathrm{E}\left(\mathrm{M} \theta_{\mathrm{I}}\right)^{\gamma}-\mathrm{W}_{\mathrm{L}}-\beta \mathrm{V}_{3}{ }^{\mathrm{I}} /(1+\beta)$ and $\left(\mathrm{p}_{\mathrm{IH}} / \mathrm{p}_{\mathrm{IL}}\right)\left[\mathrm{E}\left(\mathrm{M} \theta_{\mathrm{I}}\right)^{\gamma}-\right.$ $\left.\mathrm{W}_{\mathrm{H}}-\beta \mathrm{V}_{2}^{\mathrm{I}} /\left(1+\beta+\beta^{2}\right)\right]>\mathrm{E}\left(\mathrm{M} \theta_{\mathrm{I}}\right)^{\gamma}-\mathrm{W}_{\mathrm{L}}-\beta \mathrm{V}_{2}^{\mathrm{I}} /\left(1+\beta+\beta^{2}\right)$, respectively. For the preceding two inequalities, both the left-hand and right-hand sides are functions of $\gamma$, defined on $[0,1]$, that are monotonically increasing and convex in $\gamma$, crossing at most once, with the function on the left-hand side increasing more rapidly than the function on the right-hand side.

If $\gamma_{\mathrm{I} 3}=0$, then $\gamma_{\mathrm{I} 2} \geq \gamma_{\mathrm{I} 3}$. If $\gamma_{\mathrm{I} 3}=1$, then $\left(\mathrm{p}_{\mathrm{IH}} / \mathrm{p}_{\mathrm{IL}}\right)\left[\mathrm{E}\left(\mathrm{M} \theta_{\mathrm{I}}\right)^{\gamma}-\mathrm{W}_{\mathrm{H}}\right] \leq\left[\mathrm{E}\left(\mathrm{M} \theta_{\mathrm{I}}\right)^{\gamma}-\mathrm{W}_{\mathrm{L}}\right] \forall \gamma$. This implies $\left(\mathrm{p}_{\mathrm{IH}} / \mathrm{p}_{\mathrm{IL}}\right)\left[\mathrm{E}\left(\mathrm{M} \theta_{\mathrm{I}}\right)^{\gamma}-\mathrm{W}_{\mathrm{H}}-\beta \mathrm{V}_{3}^{\mathrm{I}} /(1+\beta)\right] \leq \mathrm{E}\left(\mathrm{M} \theta_{\mathrm{I}}\right)^{\gamma}-\mathrm{W}_{\mathrm{L}}-\beta \mathrm{V}_{3}^{\mathrm{I}} /(1+\beta) \forall \gamma$, so $\gamma_{\mathrm{I} 2}=1$. Recall that, if $0<\gamma_{\mathrm{I} 3}<1$ and $0<\gamma_{\mathrm{I} 2}<1, \gamma_{\mathrm{I}}$ is the value of $\gamma$ that solves $\left(\mathrm{p}_{\mathrm{IH}} / \mathrm{p}_{\mathrm{IL}}\right)\left[\mathrm{E}\left(\mathrm{M} \theta_{\mathrm{I}}\right)^{\gamma}-\right.$ $\left.\mathrm{W}_{\mathrm{H}}\right]-\left[\mathrm{E}\left(\mathrm{M} \theta_{\mathrm{I}}\right)^{\gamma}-\mathrm{W}_{\mathrm{L}}\right]=0$, whereas $\gamma_{\mathrm{I} 2}$ is the value of $\gamma$ that solves $\left(\mathrm{p}_{\mathrm{IH}} / \mathrm{p}_{\mathrm{IL}}\right)\left[\mathrm{E}\left(\mathrm{M} \theta_{\mathrm{I}}\right)^{\gamma}-\right.$ $\left.\mathrm{W}_{\mathrm{H}}\right]-\left[\mathrm{E}\left(\mathrm{M} \theta_{\mathrm{I}}\right)^{\gamma}-\mathrm{W}_{\mathrm{L}}\right]=\left(\mathrm{p}_{\mathrm{IH}} / \mathrm{p}_{\mathrm{IL}}-1\right) \beta \mathrm{V}_{3}^{\mathrm{I}} /(1+\beta)$. The right-hand side of the preceding equation is positive, and the left-hand side would equal zero if evaluated at $\gamma=\gamma_{13}$, so $\gamma_{13}$ $<\gamma_{\mathrm{I} 2}$, since the left-hand side of the equation is monotonically increasing in $\gamma$.

If $\gamma_{\mathrm{I} 2}=0$, then $\gamma_{\mathrm{I} 1} \geq \gamma_{\mathrm{I} 2}$. If $\gamma_{\mathrm{I} 2}=1$, then $\left(\mathrm{p}_{\mathrm{IH}} / \mathrm{p}_{\mathrm{IL}}\right)\left[\mathrm{E}\left(\mathrm{M} \theta_{\mathrm{I}}\right)^{\gamma}-\mathrm{W}_{\mathrm{H}}-\beta \mathrm{V}_{3}^{\mathrm{I}} /(1+\beta)\right] \leq \mathrm{E}\left(\mathrm{M} \theta_{\mathrm{I}}\right)^{\gamma}-$ $\mathrm{W}_{\mathrm{L}}-\beta \mathrm{V}_{3}^{\mathrm{I}} /(1+\beta) \forall \gamma$. This implies $\left(\mathrm{p}_{\mathrm{IH}} / \mathrm{p}_{\mathrm{IL}}\right)\left[\mathrm{E}\left(\mathrm{M} \theta_{\mathrm{I}}\right)^{\gamma}-\mathrm{W}_{\mathrm{H}}-\beta \mathrm{V}_{2}^{\mathrm{I}} /\left(1+\beta+\beta^{2}\right)\right] \leq\left[\mathrm{E}\left(\mathrm{M} \theta_{\mathrm{I}}\right)^{\gamma}-\right.$ $\left.\mathrm{W}_{\mathrm{L}}-\beta \mathrm{V}_{2}^{\mathrm{I}} /\left(1+\beta+\beta^{2}\right)\right] \forall \gamma$, since $\mathrm{V}_{2}^{\mathrm{I}}(0)>\mathrm{V}_{3}{ }^{\mathrm{I}}\left(1+\beta+\beta^{2}\right) /(1+\beta)$, so $\gamma_{\mathrm{I} 1}=1$. To see that $\mathrm{V}_{2}{ }^{\mathrm{I}}>$ $\mathrm{V}_{3}^{\mathrm{I}}\left(1+\beta+\beta^{2}\right) /(1+\beta)$, as claimed in the preceding sentence, consider the case $\beta=1$ (the most difficult case, since the RHS is largest) so that the inequality becomes $\mathrm{V}_{2}{ }^{\mathrm{I}}>$ $(3 / 2) V_{3}{ }^{I}$. Comparing the expressions for $V_{2}{ }^{I}$ and $V_{3}{ }^{I}$ when $\beta=1$, it is clear that simply by making the same wage offer in Period 2 that is optimal in Period 3 (even if such a wage offer is not optimal in Period 2) the employer guarantees that the maximand of $\mathrm{V}_{2}{ }^{\mathrm{I}}$ is more than twice the maximand of $\mathrm{V}_{3}{ }^{\mathrm{I}}$, so that the inequality $\mathrm{V}_{2}{ }^{\mathrm{I}}>(3 / 2) \mathrm{V}_{3}{ }^{\mathrm{I}}$ must hold, and therefore $\mathrm{V}_{2}{ }^{\mathrm{I}}>\mathrm{V}_{3}{ }^{\mathrm{I}}\left(1+\beta+\beta^{2}\right) /(1+\beta)$ must also hold. Recall that, if $0<\gamma_{\mathrm{I} 2}<1$ and $0<\gamma_{\mathrm{I} 1}<$ $1, \gamma_{\mathrm{I} 2}$ is the value of $\gamma$ that solves $\left(\mathrm{p}_{\mathrm{IH}} / \mathrm{p}_{\mathrm{IL}}\right)\left[\mathrm{E}\left(\mathrm{M} \theta_{\mathrm{I}}\right)^{\gamma}-\mathrm{W}_{\mathrm{H}}\right]-\left[\mathrm{E}\left(\mathrm{M} \theta_{\mathrm{I}}\right)^{\gamma}-\mathrm{W}_{\mathrm{L}}\right]=\left(\mathrm{p}_{\mathrm{IH}} / \mathrm{p}_{\mathrm{IL}}-\right.$ 1) $\beta \mathrm{V}_{3}^{\mathrm{I}}(0) /(1+\beta)$, whereas $\gamma_{\mathrm{I} 1}$ is the value of $\gamma$ that solves $\left(\mathrm{p}_{\mathrm{IH}} / \mathrm{p}_{\mathrm{IL}}\right)\left[\mathrm{E}\left(\mathrm{M} \theta_{\mathrm{I}}\right)^{\gamma}-\mathrm{W}_{\mathrm{H}}\right]-$ $\left.\left[\mathrm{E}\left(\mathrm{M} \theta_{\mathrm{I}}\right)^{\gamma}-\mathrm{W}_{\mathrm{L}}\right]=\left(\mathrm{p}_{\mathrm{IH}} / \mathrm{p}_{\mathrm{IL}}-1\right) \beta \mathrm{V}_{2}^{\mathrm{I}} /\left(1+\beta+\beta^{2}\right)\right]$. Since $\mathrm{V}_{2}^{\mathrm{I}}>\mathrm{V}_{3}^{\mathrm{I}}\left(1+\beta+\beta^{2}\right) /(1+\beta), \gamma_{\mathrm{I} 2}<\gamma_{\mathrm{I} 1}$ since the left-hand side of the preceding equation is monotonically increasing in $\gamma$.

The preceding statements collectively imply $0 \leq \gamma_{\mathrm{I} 3} \leq \gamma_{\mathrm{I} 2} \leq \gamma_{\mathrm{I} 1} \leq 1$, and the last sentence of the proposition follows directly from the definitions of the $\gamma_{\mathrm{It}}$. 


\section{Proof of Proposition 2:}

Given the parameters, employer i with $\gamma=\gamma_{i}$ chooses informal methods if $\max \left[\mathrm{V}_{1}{ }^{\mathrm{I}}, \mathrm{V}_{1}{ }^{\mathrm{F}}\right]$ $=\mathrm{V}_{1}{ }^{\mathrm{I}}$, formal methods if $\max \left[\mathrm{V}_{1}{ }^{\mathrm{I}}, \mathrm{V}_{1}^{\mathrm{F}}\right]=\mathrm{V}_{1}^{\mathrm{F}}$, and is indifferent between the two methods if $\max \left[\mathrm{V}_{1}{ }^{\mathrm{I}}, \mathrm{V}_{1}{ }^{\mathrm{F}}\right]=\mathrm{V}_{1}{ }^{\mathrm{I}}=\mathrm{V}_{1} \mathrm{~F}^{\mathrm{F}}$. Furthermore, $\max \left[\mathrm{V}_{1}{ }_{1}, \mathrm{~V}_{1}{ }^{\mathrm{F}}\right]>0$ for all $\gamma$, given that is assumed to be always profitable to search (i.e. to choose a recruitment method and post a wage). This verifies the first statement.

See Table 3 for an example of a set of parameters for which both strategies are potentially observable in the labor market. Alternatively, suppose that the differences between informal and formal methods both in hiring probabilities and in the means of $\theta_{\mathrm{I}}$ and $\theta_{\mathrm{F}}$ are small but that $\sigma$ is large. Since the value of sampling the second order statistic of $\theta_{\mathrm{F}}$ increases in the variance of $\theta_{\mathrm{F}}$, for sufficiently large values of $\sigma$ only formal methods will be chosen regardless of $\gamma$. Alternatively, suppose that the hiring probabilities are near zero for formal methods and near one for informal methods. Then for most configurations of the remaining parameters, only informal methods will be chosen regardless of the value of $\gamma$. These 3 examples verify the first part of the second statement.

To verify the second part of the second statement, and also the third statement, observe that given the parameter values both $\mathrm{V}_{1}{ }^{\mathrm{I}}$ and $\mathrm{V}_{1}{ }^{\mathrm{F}}$ are continuous and monotonically increasing in $\gamma$ on the interval $[0,1]$, since the expressions for expected per-period profit (regardless of recruitment choice) are continuous and monotonically increasing in $\gamma$ on the interval $[0,1]$. Thus, if $\mathrm{V}_{1}{ }^{\mathrm{I}}$ lies everywhere above (below) $\mathrm{V}_{1}{ }^{\mathrm{F}}$ on $[0,1]$, all employers choose informal (formal) methods, so there cannot exist thresholds of type $\gamma_{\text {IFk }}^{*}$ or of type $\gamma^{*}$ Fik in $[0,1]$, and if $\mathrm{V}_{1}^{\mathrm{I}}$ crosses $\mathrm{V}_{1}^{\mathrm{F}}$ from above (below), the value of $\gamma$ at the intersection is a threshold of type $\gamma_{\mathrm{IFk}}^{*}\left(\gamma_{\mathrm{FIK}}^{*}\right)$. If a threshold is of type $\gamma_{\mathrm{IFk}}^{*}\left(\gamma_{\mathrm{FIk}}^{*}\right)$ all employers with values of $\gamma$ above this (until the next threshold of the opposite type, if one exists) choose formal (informal) methods and all employers with values of $\gamma$ below this (until the next threshold of the opposite type, if one exists) choose informal (formal) methods. Thus, the set of all thresholds of either type partitions the interval $[0,1]$ into subintervals that alternate between the two recruitment methods.

\section{Condition to Ensure Positive Expected Profit from Searching:}

Positive expected profit from search using informal methods and a low wage offer requires $\mathrm{E} \theta_{\mathrm{I}}^{\gamma}>\mathrm{W}_{\mathrm{L}} / \mathrm{M}^{\gamma}$. Given that $\theta_{\mathrm{I}}$ is distributed lognormal, $\mathrm{E} \theta_{\mathrm{I}}=\exp \left(\mu_{1}+\sigma_{1}{ }^{2} / 2\right)$, or $\mu=$ $\exp \left(\mu_{1}+\sigma_{1}{ }^{2} / 2\right)$, or $\mu_{1}=\ln (\mu)-\sigma_{1}{ }^{2} / 2$, where $\mu_{1}$ and $\sigma_{1}{ }^{2}$ are the mean and variance of $\ln \left(\theta_{\mathrm{I}}\right)$. It can be shown that $\mathrm{E}_{\mathrm{I}}^{\gamma}=\exp \left(\gamma \mu_{1}+\gamma^{2} \sigma_{1}^{2} / 2\right)$. Thus, the required condition is $\exp \left(\gamma \mu_{1}+\gamma^{2} \sigma_{1}^{2} / 2\right)>\mathrm{W}_{\mathrm{L}} / \mathrm{M}^{\gamma}$, or $\gamma(1-\gamma) \sigma_{1}^{2}<2\left[\ln \left((\mathrm{M} \mu)^{\gamma} / \mathrm{W}_{\mathrm{L}}\right)\right]$. The preceding inequality holds if $\gamma$ equals 0 or 1 , since its right-hand side is positive given the assumptions $\mathrm{W}_{\mathrm{L}}<$ $1, \mu>1$, and $\mathrm{M} \geq 1$. If $0<\gamma<1$, then the inequality holds if $\sigma_{1}{ }^{2}<\mathrm{m}\left(\gamma ; \mathrm{M}, \mu, \mathrm{W}_{\mathrm{L}}\right)$ where $\mathrm{m}=2 \ln \left((\mathrm{M} \mu)^{\gamma} / \mathrm{W}_{\mathrm{L}}\right) /[\gamma(1-\gamma)]$. Now, using $\sigma^{2}=\left(\exp \left(\sigma_{1}^{2}\right)-1\right) \exp \left(2 \mu_{1}+\sigma_{1}{ }^{2}\right)$ and $\mu_{1}=$ $\ln (\mu)-\sigma_{1}{ }^{2} / 2$, the required condition on $\sigma_{1}{ }^{2}$ can be restated as $\sigma^{2}<\mathrm{k}\left(\gamma ; \mathrm{M}, \mu, \mathrm{W}_{\mathrm{L}}\right)$ where $\mathrm{k}$ $=\mu^{2}[\exp (\mathrm{m})-1]$. Thus, for the case of a lognormal $\theta_{\mathrm{I}}$, any employer can always guarantee a positive expected profit from searching (by choosing informal methods and a 
low wage offer) as long as $\sigma^{2}$ is not too large. Let $\gamma_{0}$ denote the value of $\gamma$ that minimizes $\mathrm{m}$ (and $\mathrm{k})$. The following first-order condition of $\mathrm{m}$ with respect to $\gamma$ defines $\gamma_{0}$ :

$\gamma_{0}{ }^{2} \ln (\mathrm{M} \mu)+\ln \left(\mathrm{W}_{\mathrm{L}}\right)\left(1-2 \gamma_{0}\right)=0$. It can be shown, after some algebra, that the secondorder condition is satisfied, so that $\gamma_{0}$ is a minimum. In the estimation, the constraint on $\sigma$ never comes close to binding. The constraint was not imposed in estimation, and the result (fixing $\mathrm{W}_{\mathrm{L}}=0.7404$ ) was $\mathrm{M}=20.144$ and $\mu=1.131$, implying $\gamma_{0} \approx 0.228$, which in turn implies $\mathrm{m} \approx 11.514$. Thus, the smallest value of the upper bound on $\sigma$ (given the values of $\mathrm{M}, \mu$, and $\left.\mathrm{W}_{\mathrm{L}}\right)$ is $\mathrm{k}^{1 / 2} \approx(128,010)^{1 / 2} \approx 357.785$, and the estimated value of $\sigma$ is 0.445 . Intuitively, the reason the constraint on $\sigma$ that ensures positive expected profit is never relevant in the estimation is that the second order statistic of $\theta_{\mathrm{I}}$ increases rapidly in $\sigma$, so that $\sigma$ must be relatively small, since otherwise formal methods would always be the dominant recruitment strategy. 


\section{APPENDIX B}

The tables below are based on the subsample of 719 workers in "marketing, sales, and service" occupations in positions not requiring a college degree (392 are in services and 327 are in marketing and sales). The results are roughly similar in many respects to those for clerical workers but with some differences. As seen in Table B.1, average vacancy duration is longer for workers hired via formal methods than via informal methods, and the applicant pool is larger as measured by the number of applicants and number of interviews for the position into which the most recent worker was hired. However, starting wages are only negligibly higher for formal methods than for informal methods. The pattern of structural estimates in Table B.2 does not differ dramatically from those in Table 3 based on clerical workers, though there are some differences. For example, the estimated value of $\mathrm{M}$ is lower in Table B.2 than in Table 3, though note that I fix $\mathrm{W}_{\mathrm{H}}$ and $\mathrm{W}_{\mathrm{L}}$ at lower values in the new occupational subsample, since workers in this group have lower average wages than clericals. As with clerical workers, I set these values so that $\mathrm{W}_{\mathrm{H}} / \mathrm{W}_{\mathrm{L}}$ equals the corresponding ratio of the 0.75 and 0.25 quantiles of the actual starting wage distribution for workers in this occupational aggregate. As seen in Table B.3, the fit is not quite as good in this subsample as in the subsample of clericals.

Table B.1: Descriptive Statistics by Recruitment Method

\begin{tabular}{|l|l|l|l|}
\hline & Informal & Formal & Difference \\
\hline Vacancy Duration (Weeks) & 1.586 & 1.739 & -0.153 \\
& $(0.137)$ & $(0.098)$ & $(0.168)$ \\
\hline Real Hourly Starting Wage (\$1990) & 6.189 & 6.219 & -0.030 \\
& $(0.186)$ & $(0.168)$ & $(0.251)$ \\
\hline Number of Applicants & 26.289 & 52.511 & -26.222 \\
& $(8.319)$ & $(13.079)$ & $(15.501)$ \\
\hline Number of Interviews & 7.713 & 14.286 & -6.573 \\
& $(2.055)$ & $(3.871)$ & $(4.383)$ \\
\hline Total sample size $=N_{I}+N_{F}=719$ & $N_{I}=256$ & $N_{F}=463$ & \\
\hline
\end{tabular}

Notes: Cell entries are means, with standard errors in parentheses. First column is the subsample generated via informal methods, and second column is the subsample generated by some other means (e.g. newspaper advertisements). Sampling weights are used.

\section{Table B.2: Structural Parameter Estimates ${ }^{1}$}

\begin{tabular}{l|c|}
\hline Parameters & Asymptotic Standard Errors \\
\hline $\mathrm{M}=17.024$ & 2.363 \\
$\alpha_{\gamma}=0.666$ & 0.102 \\
$\beta_{\gamma}=0.965$ & 0.003 \\
$\mu=1.107$ & 0.013 \\
$\sigma=0.440$ & 0.028 \\
$\mathrm{p}_{\mathrm{IH}}=0.980$ & 0.131 \\
$\mathrm{p}_{\mathrm{IL}}=0.633$ & 0.092 \\
$\mathrm{p}_{\mathrm{FH}}=0.801$ & 0.101 \\
$\mathrm{p}_{\mathrm{FL}}=0.655$ & 0.100 \\
\hline
\end{tabular}

${ }^{1}$ The restrictions imposed in estimation are: $\mathrm{W}_{\mathrm{H}}=0.8952$;

$\mathrm{W}_{\mathrm{L}}=0.5148 ; \mathrm{p}_{\mathrm{IH}}>\mathrm{p}_{\mathrm{IL}} ; \mathrm{p}_{\mathrm{FH}}>\mathrm{p}_{\mathrm{FL}} ; \mathrm{p}_{\mathrm{IH}}>\mathrm{p}_{\mathrm{FH}} ; \mathrm{p}_{\mathrm{IL}}>\mathrm{p}_{\mathrm{FL}} ;$

$\mathrm{E}\left(\theta_{\mathrm{F}}\right)=1 ; \mathrm{E}\left(\theta_{\mathrm{I}}\right)=\mu>1 ; \operatorname{Var}\left(\theta_{\mathrm{I}}\right)=\operatorname{Var}\left(\theta_{\mathrm{F}}\right)=\sigma ;$ and $\beta=1$. 
Table B.3: Goodness of Fit

\begin{tabular}{|c|c|c|c|c|c|}
\hline Cell & Recruitment Strategy & Hiring Period & Starting Wage & $\%$ Observed & $\%$ Predicted \\
\hline 1 & Informal Methods & Period 1 & High & 13.49 & 12.10 \\
\hline 2 & Informal Methods & Period 2 & High & 2.82 & 0.30 \\
\hline 3 & Informal Methods & Period 3 & High & 1.07 & 0.00 \\
\hline 4 & Informal Methods & Period 1 & Low & 15.85 & 13.80 \\
\hline 5 & Informal Methods & Period 2 & Low & 0.94 & 4.70 \\
\hline 6 & Informal Methods & Period 3 & Low & 0.15 & 1.10 \\
\hline 7 & Informal Methods & Not Hired & -- & 0.16 & 0.50 \\
\hline 8 & Formal Methods & Period 1 & High & 24.73 & 23.10 \\
\hline 9 & Formal Methods & Period 2 & High & 5.85 & 6.60 \\
\hline 10 & Formal Methods & Period 3 & High & 2.13 & 1.80 \\
\hline 11 & Formal Methods & Period 1 & Low & 31.56 & 26.10 \\
\hline 12 & Formal Methods & Period 2 & Low & 0.79 & 7.00 \\
\hline 13 & Formal Methods & Period 3 & Low & 0.46 & 1.50 \\
\hline 14 & Formal Methods & Not Hired & -- & 0.00 & 1.40 \\
\hline
\end{tabular}

Note: The model cannot be rejected on the basis of a chi-square test of goodness of fit. The test statistic is $0.5 \times \mathrm{Q} \times \mathrm{N}=3.651$, where $\mathrm{Q}=0.0102$ is the value of the minimized distance function, and $\mathrm{N}=719$ is the sample size. Test statistic is distributed $\chi^{2}(n-k-1)$ where $n$ is the number of cells (14) and $\mathrm{k}$ is the number of estimated parameters (9). $\mathrm{p}$-value $=0.455$. 